\title{
De Jeanne d'Arc à Madelaine de Verchères la femme guerrière dans la société d'ancien régime
}

\section{Diane Gervais et Serge Lusignan}

Volume 53, numéro 2, automne 1999

URI : https://id.erudit.org/iderudit/005446ar

DOI : https://doi.org/10.7202/005446ar

Aller au sommaire du numéro

Éditeur(s)

Institut d'histoire de l'Amérique française

ISSN

0035-2357 (imprimé)

1492-1383 (numérique)

Découvrir la revue

Citer cet article

Gervais, D. \& Lusignan, S. (1999). De Jeanne d'Arc à Madelaine de Verchères la femme guerrière dans la société d'ancien régime. Revue d'histoire de l'Amérique française, 53(2), 171-205. https://doi.org/10.7202/005446ar
Résumé de l'article

Malgré l'interdit fait aux femmes de participer activement au combat dans la société d'Ancien Régime, il était parfois acceptable qu'elles interviennent activement par les armes, lorsqu'une situation militaire devenait critique. Le processus par lequel une femme se faisait soldat était très bien codé et peut être comparé aux rituels d'inversion des rôles décrits par les anthropologues. L'article examine le cas de trois femmes guerrières: Jeanne d'Arc, qui combattit les Anglais pour le compte de Charles VII, Jeanne Hachette, qui participa à la défense de Beauvais (France) lors du siège dirigé par le duc de Bourgogne en 1472, et Madeleine de Verchères, qui se battit pour défendre le fort de son père contre une attaque des Iroquois en 1692. L'analyse met en lumière un processus en trois étapes au cours duquel la femme devient guerrière. Premièrement, on distingue une courte période de rupture durant laquelle elle cesse de se comporter en femme et fait accepter sa nouvelle conduite comme soldat par le groupe social. Dans un deuxième temps, qui dure aussi longtemps que pèse la menace, elle participe activement au combat contre les ennemis. Une dernière étape du processus a pour fonction de la ramener à son état féminin antérieur. L'article est complété par une nouvelle édition des deux lettres de Madeleine de Verchères.
Tous droits réservés @ Institut d'histoire de l'Amérique française, 1999

Ce document est protégé par la loi sur le droit d'auteur. L'utilisation des services d'Érudit (y compris la reproduction) est assujettie à sa politique d'utilisation que vous pouvez consulter en ligne.

https://apropos.erudit.org/fr/usagers/politique-dutilisation/ 


\title{
DE JEANNE D'ARC À MADELEINE DE VERCHÈRES LA FEMME GUERRIÈRE DANS LA SOCIÉTÉ D'ANCIEN RÉGIME
}

\begin{abstract}
DIANE GERVAIS
IREP

SERGE LUSIGNAN

Département d'histoire

RÉSUMÉ

Université de Montréal

Malgré l'interdit fait aux femmes de participer activement au combat dans la société d'Ancien Régime, il était parfois acceptable qu'elles interviennent activement par les armes, lorsqu'une situation militaire devenait critique. Le processus par lequel une femme se faisait soldat était très bien codé et peut être comparé aux rituels d'inversion des rôles décrits par les anthropologues. L'article examine le cas de trois femmes guerrières: Jeanne d'Arc, qui combattit les Anglais pour le compte de Charles VII, Jeanne Hachette, qui participa à la défense de Beauvais (France) lors du siège dirigé par le duc de Bourgogne en 1472, et Madeleine de Verchères, qui se battit pour défendre le fort de son père contre une attaque des Iroquois en 1692. L'analyse met en lumière un processus en trois étapes au cours duquel la femme devient guerrière. Premièrement, on distingue une courte période de rupture durant laquelle elle cesse de se comporter en femme et fait accepter sa nouvelle conduite comme soldat par le groupe social. Dans un deuxième temps, qui dure aussi longtemps que pèse la menace, elle participe activement au combat contre les ennemis. Une dernière étape du processus a pour fonction de la ramener à son état féminin antérieur. L'article est complété par une nouvelle édition des deux lettres de Madeleine de Verchères.
\end{abstract}

\section{ABSTRACT}

Despite the general prohibition against the active participation of women in war during the Old Regime, it was perfectly acceptable that they take up arms when confronted with a critical military situation. The process by which a woman became a soldier was stricly coded and can be compared to rituals of inversion as studied by anthropologists. The paper analyses three cases of women warriors: Joan of Arc who fought against the English army for Charles VII, Jeanne Hachette who took part in the defense of the town of Beauvais (France) during a siege conducted by the duke of Burgundy in 1472, and Madeleine de Verchères who fought to protect her father's fort from an attack by Iroquois in 1692. An examination of these three cases reveal a three step process by which a woman becomes a soldier. The process begins with a brief interval during which womanly behavior is set aside and the woman convinces society to accept her new behavior as a soldier. During a second period, which lasts as long as the military threat persists, she actively wages war against the ennemy. During the last step in the process, she returns to her earlier womanly status. The paper is complemented by a new edition of the two letters written by Madeleine de Verchères. 
Dans la longue histoire de l'Occident, le combat guerrier a normalement été interdit aux femmes ${ }^{1}$. Pourtant, dès le $\mathrm{VI}^{\mathrm{e}}$ siècle avant Jésus-Christ, l'art et la littérature grecs développèrent le mythe des Amazones, cette tribu de guerrières qui habitaient des terres aux confins du monde civilisé ${ }^{2}$. L'Ancien Testament chrétien retint, pour sa part, le livre de Judith qui raconte comment cette femme juive parvint, par la ruse, à approcher et à tuer Holopherne, le chef de l'armée assyrienne qui assiégeait Béthulie, la ville de son peuple ${ }^{3}$. L'interdit fut plusieurs fois contourné dans l'histoire.

Un dictionnaire récent, The Encyclopedia of Amazons, a tenté un relevé des femmes guerrières dans l'histoire. Malgré son caractère sommaire, il offre une approximation sans doute acceptable du phénomène. Pour l'Europe et l'Amérique du Nord, il dénombre 18 personnages au $\mathrm{XV}^{\mathrm{e}}$ siècle, 24 au $\mathrm{XVI}^{\mathrm{e}}$ siècle et 18 au XVII ${ }^{\mathrm{e}}$ siècle ${ }^{4}$. Au total: 60 femmes. Pour 58 d'entre elles, le vieux continent fut le théâtre de leurs exploits et 2 seulement combattirent en terre d'Amérique, soit Françoise-Marie Jacquelin de La Tour et Madeleine de Verchères ${ }^{5}$. La lecture des notices biographiques fait ressortir différents cas de figure. Quelques-unes, nobles, ont accompagné leur mari dans leurs guerres, ou ont parfois dirigé une armée. Exceptionnellement, certaines ont été femmes soldats comme Jeanne d'Arc. De façon générale, les femmes furent les protagonistes de combats désespérés. La majorité ont lutté pour la défense de leur espace proche, ville, château ou domaine, souvent lorsqu'il y avait un déficit

1. Pour un survol des approches anthropologiques de l'interdit de la guerre aux femmes, voir la mise au point de D. Meintel, «Victimes ou protagonistes: les femmes et la guerre», Anthropologie et sociétés, 7,1 (1983) : 179-186. Nous citerons en cours de texte les travaux dont nous nous sommes inspirés. Nous remercions nos collègues Denyse Baillargeon et Thomas Wien d'avoir relu ce texte et de nous avoir fait d'utiles suggestions, et Virginie Portes qui en a fait la dernière révision. Une version allégée de la seconde partie de cet article a été présentée au Colloque Situazioni d'assedio, tenu à Montalcino (Italie), du 7 au 10 juillet 1999.

2. W. B. Tyrrell, Amazons. A Study in Athenian Mythmaking (Baltimore/Londres, The Johns Hopkins University Press, 1984).

3. Le livre de Judith ne fut toutefois pas retenu par la Bible hébraïque et il fut exclu de la Bible des Protestants. Voir La Bible de Jérusalem (Paris, Les Éditions du Cerf, 1988), 533535 , pour un bref rappel historique, et 551-565, pour le texte.

4. J. A. Salmonson, The Encyclopedia of Amazons (New York, Doubleday, 1992). Les données numériques sont tirées d'une base informatique qu'a constituée pour nous Virginie Portes, à partir du dictionnaire. Les données sur notre période contredisent la thèse de M. McLaughlin qui veut que le nombre de femmes guerrières diminue à la fin du Moyen Âge. Cette remarque n'enlève rien à la qualité de son analyse sur la place de ce phénomène au sein de la société féodale. Voir M. McLaughlin, «The Woman Warrior: Gender, Warfare and Society in Medieval Europe», Women's Studies. An Interdisciplinary Journal, 17 (1989) : 193-209.

5. L'Acadie fut le théâtre des exploits de Françoise-Marie Jacquelin de La Tour. Le Dictionnaire biographique du Canada traite de ce personnage sous la rubrique «Saint-Étienne de La Tour (Charles de)»(Québec, Les Presses de l’Université Laval, 1967), 1: 606-610. 
d'hommes pour défendre la place. L'état de siège constitue l'occasion la plus favorable pour que les femmes se transforment momentanément en guerrière. L'efficacité de leur action tient fréquemment au sursaut de vaillance qu'elles suscitent chez les défenseurs, plutôt qu'au nombre d'ennemis qu'elles abattent. Le temps de leur engagement dépasse rarement celui de la résistance. Leur prise d'armes reste temporaire et elle n'altère en rien leur féminité. L'intervention féminine s'inscrit dans le registre de l'exemplarité et de l'héroïsme.

Quelques cas de femmes guerrières de la fin du Moyen Âge et des Temps Modernes ont donné lieu à une mise par écrit des faits et des perceptions qu'en eurent les protagonistes et leurs contemporains, dans des textes particulièrement significatifs. Ces documents sont certes précieux pour fixer les événements, mais ils le sont peut-être encore plus parce qu'ils livrent l'image que se firent une époque et une culture du phénomène. Nous nous intéresserons dans le présent article au système de valeurs et de représentations qui se dégage des textes concernant trois personnages: Madeleine de Verchères, dont l'histoire nous servira de guide, Jeanne Hachette, qu'on a si souvent rapprochée de celle-ci, et Jeanne d'Arc, qui poussa l'expérience audelà des limites permises.

Bien que deux siècles et demi séparent la première de la troisième et que la géographie les éloigne toutes, leur geste s'inscrit dans un même cadre. Elles évoluèrent dans un espace politique défini par la souveraineté du roi de France et par les institutions administratives d'Ancien Régime ${ }^{6}$. Elles adhéraient toutes trois au christianisme de l'Église catholique. En outre, la charge expressive de nos sources textuelles montre qu'elles vécurent dans une société fondée sur la distinction des rôles masculin et féminin et sur le tabou attaché à sa transgression. Ces traits communs, sur lesquels nous allons longuement revenir, nous permettent de rapprocher ces trois cas emblématiques, afin d'analyser ce que l'expérience de la femme guerrière nous révèle des tensions inhérentes à la différenciation sexuelle des rôles dans la société d'Ancien Régime. En même temps, apparaît de façon saisissante la constance dans le temps et dans l'espace de logiques sociales particulièrement tenaces. Avant de poursuivre notre

6. Le renouvellement des perspectives dans l'histoire politique et institutionnelle de la France, qui s'est opéré depuis deux ou trois décennies, invite à insister davantage sur la continuité que sur la rupture dans l'histoire du politique entre le $\mathrm{XIV}^{\mathrm{e}}$ et le XVII $\mathrm{Xiècle}^{\mathrm{I}} \mathrm{Il}$ faut lire en parallèle à ce sujet l'introduction d'A. Rigaudière à Pouvoirs et institutions dans la France médiévale. Des temps féodaux aux temps de l'État (Paris, Armand Colin, 1994), 5-6, et celle de F. Bluche à L'Ancien Régime. Institutions et société (Paris, Livre de Poche, nº 0501, 1993), 7-12. 
analyse, rappelons brièvement l'histoire de chacune et les sources qui nous les font connaître.

\section{MADELEINE DE VERCHÈRES, JEANNE D'ARC ET JEANNE HACHETTE: L'HISTOIRE ET LES SOURCES}

Madeleine de Verchères a raconté son exploit dans une lettre qu'elle adressa, en 1699, à la comtesse de Maurepas, afin d'obtenir une pension du roi Louis XIV 7 . Un matin d'octobre 1692, les Iroquois, cachés dans les buissons aux environs du fort de Verchères, surprirent les habitants qui travaillaient aux champs ${ }^{8}$. Ils en firent prisonniers une vingtaine, et Madeleine, qui se trouvait à quatre cents pas du fort, fut poursuivie jusqu'aux portes par un Iroquois qui la saisit par son mouchoir de col. Le dénouant prestement, elle le lui laissa entre les mains et se précipita à l'intérieur en criant: «Aux armes!». Elle n'avait que 14 ans et elle se trouvait quasiment seule avec ses deux jeunes frères, un domestique, un vieillard de 80 ans et deux soldats. Le fort n'était qu'une palissade de pieux, percée d'une seule porte donnant sur le fleuve Saint-Laurent, avec à chaque angle un bastion, et à

7. Nous utilisons la version de cette lettre qui se trouve aux Archives nationales du Canada, collection Moreau de Saint-Méry, Archives des Colonies, série F 3, vol. 4, folio 341, bobine 7930. Nous proposons en annexe 1 notre propre transcription de la lettre, car celle éditée par É. Richard, Rapport sur les archives canadiennes, Supplément, 1899, 6-7, prend trop de libertés avec l'orthographe du document. La vie de Madeleine de Verchères a donné lieu à de nombreuses publications qui tiennent plus souvent du récit héroïque que de l'histoire. Nous avons particulièrement tiré profit des articles d'A. Vachon, «Jarret de Verchères, Marie-Madeleine», Dictionnaire biographique du Canada (Québec, Les Presses de l'Université Laval, 1969), III : 331-337; de F. A. Baillargé, Marie-Madeleine de Verchères et les siens (Verchères, $1913)$; et de quelques autres contributions citées en cours d'analyse. Nous remercions tout particulièrement Patrice Groulx qui nous a facilité grandement la recherche bibliographique pour la reconstitution de la légende de Madeleine de Verchères.

8. On trouve une allusion aux événements racontés par Madeleine dans la Relation de ce qui s'est passé en Canada depuis le mois de septembre 1692 jusqu'au départ des vaisseaux en 1693: "Mr de Calliere resolut donc suivant les ordres de Mr le Comte d'envoyer ravitailler Chambly et depescha un canot pour visiter les passages de la rivière de Richelieu ou l'on apprehendons avec apparence que des batteaux chargez ne trouvassent pas assez d'eau, ce canot a son retour eut connaissance que les ennemis avoient tué et pris prisonniers quelques personnes à Vercheres, emmené les bestiaux dans le bois et levé la chevelure à un soldat à St-Ours. On jugea que ce ne pouvoit estre qu'un petit party détaché du gros. » (Archives nationales du Canada, Archives des colonies, série C 11 A, vol. 12-1, bob. 6062). Les faits racontés dans la première lettre sont authentifiés par l'intendant Champigny dans la correspondance officielle de la colonie, Lettre du 15 octobre 1700 (Archives des colonies, série C 11 A, vol. 18, bobine 6068). Le récit de Madeleine fut repris dans des termes très semblables par Bacqueville de la Potherie dans son Histoire de l'Amérique septentrionale sans doute achevée en 1702 et publiée en 1722. A. Vachon (loc. cit.) a posé, sans le résoudre, le problème des influences littéraires entre celui-ci, qui avait marié la fille du seigneur de Saint-Ours, et Madeleine. Nous n'avons rien à ajouter à ce débat. 
l'intérieur, la maison du seigneur, quelques bâtiments et une redoute qui servait de corps de garde et d'entrepôt de munitions. Quelques fusils et un petit canon complétaient le dispositif de défense. Aussitôt entrée dans le fort, Madeleine organisa la résistance. Montant sur le bastion où se trouvait la sentinelle, elle se coiffa d'un chapeau de soldat et esquissa plusieurs mouvements pour laisser croire qu'un grand nombre défendait la place. Puis, elle se rendit au canon, qu'elle chargea elle-même, et tira sur les Iroquois quatre livres de balles. « $\mathrm{Ce}$ coup sy précipité», écrit-elle, eut tout le succès attendu: les Iroquois s'enfuirent et les forts voisins furent prévenus du danger.

À une date qui n'est pas antérieure à 1726, à la demande du roi transmise par le gouverneur de Beauharnois, Madeleine de Verchères raconta une seconde fois son histoire, dans un mémoire intitulé Relation des faits heroiques de Mademoiselle Marie Madelaine de Verchére contre les Iroquois aagée de quatorze ans, en l'année 1696 le $22^{e}$ octobre a huit heures du matin ${ }^{9}$. Beaucoup plus circonstancié que le premier, ce second récit raconte un état de siège qui s'étendit sur huit jours, pendant lesquels elle prit le commandement du fort, combattit, rusa avec les Iroquois et réussit même quelques sorties du fort au nez et à la barbe de l'ennemi, fusil en main, jusqu'à l'arrivée des renforts français auxquels elle rendit les armes.

Jeanne d'Arc, pour sa part, constitue l'une des figures les plus énigmatiques de l'histoire médiévale. Sa geste est très bien connue; qu'il suffise d'en rappeler l'essentiel ${ }^{10}$. Elle est née vers 1412, à Domrémy dans le duché de Bar, en Lorraine. Inspirée par des voix du ciel, elle finit par convaincre le capitaine de Vaucouleurs, Robert de Baudricourt, de lui fournir armes et compagnie pour se rendre auprès

9. Les historiens datent plutôt l'événement de 1692, puisque c'est l'année où Madeleine de Verchères eut effectivement ses 14 ans. Ajoutons qu'une escarmouche est signalée, à Verchères, dans la Relation de ce qui s'est passé... datant de la même année (loc. cit.). Cette seconde relation de Madeleine se trouve aux Archives nationales du Canada, collection Moreau de Saint-Méry, Archives des Colonies, série F 3, vol. 5, folio 434, bobine 7931. Nous l'éditons également en annexe 2. Dans son article «Jarret de Verchères, Marie-Madeleine» (loc. cit.), Vachon a suggéré que Bacqueville de la Potherie pourrait avoir soufflé à Madeleine les termes de sa première lettre. Cela nous importe peu dans la mesure où la logique interne des deux sources textuelles nous apparaît similaire. Quant à la date de la seconde lettre, qui fait référence explicite au gouverneur de Beauharnois, elle ne peut être antérieure à 1726, puisque celui-ci gouverna la Nouvelle-France entre 1726 et 1747 : Jeannette Larouche, «Beauharnois, Charles de Beauharnois de la Boische, Marquis de», The Canadian Encyclopedia (Edmonton, Hurtig Publishers, 1985), 1: 153.

10. Le cas «Jeanne d'Arc» est contaminé par une véritable pollution bibliographique alimentée par des intérêts religieux et patriotiques. Nous nous inspirons, pour tracer son histoire, de P. Champion, Procès de condamnation de Jeanne d'Arc, II : Introduction, traduction et notes (Paris, Champion, 1921); de P. Tisset, Procès de condamnation de Jeanne d'Arc, III : Introduc- 
du dauphin Charles. Elle quitta sa terre natale le 22 février 1429, pour arriver à Chinon le 4 mars. Elle rencontra le futur roi une première fois, le 8 mars, et parvint à gagner sa confiance pour qu'il lui laissât tenter sa chance de délivrer la ville d'Orléans, assiégée par les Anglais. À la suite de différentes manœuvres, elle força l'ennemi à lever le siège, le 8 mai 1429. Le second triomphe de Jeanne d'Arc fut d'ouvrir la voie jusqu'à Reims où fut couronné Charles VII, le 17 juillet 1429. La suite de son aventure fut marquée de périodes d'attente, de demi-victoires et surtout d'échecs, jusqu'à ce qu'elle fût capturée par l'ennemi, le 23 mai 1430, près de Compiègne. Par la suite remise aux autorités anglaises, elle eut à faire face à un procès canonique pour hérésie, mené par les docteurs de l'Université de Paris, sous la présidence de l'un des leurs, Pierre Cauchon, évêque de Beauvais. La procédure commença le 9 janvier 1431, et le 24 mai Jeanne fut condamnée à la prison à vie, pourvu qu'elle s'amendât et reprît ses vêtements féminins, ce qu'elle fit. Mais, une fois incarcérée, elle revint vite à ses habits d'homme, à la suite de quoi elle fut reconnue relapse. Le 30 mai 1431, elle mourut par le feu, sur la place du Vieux-Marché de Rouen.

Pour analyser Jeanne d'Arc comme figure de la femme guerrière, nous utiliserons le compte rendu de son procès de condamnation, dont on possède partiellement le texte en moyen français et la version complète en latin ${ }^{11}$.

Louis Fréchette a associé Madeleine de Verchères à Jeanne Hachette jusqu'à la substitution du prénom de Madeleine par celui de Jeanne. Il écrit en effet dans La légende d'un peuple: «... Mais Jeanne Hachette est là ! / L'héroïne si chère / à la France, chez nous c'est Jeanne de Verchère $[\text { sic }]^{12} \ldots$ » L'épisode concernant notre troisième personnage se produisit au cours des guerres entre Louis XI et Charles le Téméraire, duc de Bourgogne. Celui-ci ambitionnait de soustraire son duché à la souveraineté du roi de France, et de le rendre terri-

tion (Paris, Klincksieck, 1971); de J. Favier, «Jeanne d'Arc», La guerre de Cent Ans (Paris, Fayard, 1980), 493-528; des actes du colloque Jeanne d'Arc. Une époque, un rayonnement (Paris, Éditions du CNRS, 1982) et de l'article de S. Crane, «Clothing and Gender Definition: Joan of Arc», The Journal of Medieval and Early Modern Studies, 26 (1996): 297-320.

11. Les deux textes ont connu deux éditions au XX $\mathrm{XX}^{\mathrm{e}}$ siècle, l'une de P. Champion, Procès de condamnation de Jeanne d'Arc, I: Texte latin (Paris, Champion, 1920); l'autre de P. Tisset, Procès de condamnation de Jeanne d'Arc, I: Texte (Paris, Klincksieck, 1960). Les deux éditions nous semblent équivalentes et nous utiliserons la première. Signalons que les dépositions de Jeanne d'Arc à son procès ont largement inspiré les dialogues du film Jeanne la Pucelle de Jacques Rivette (France, 1993). Ce film est d'une rigueur historique remarquable.

12. L. Fréchette, La légende d'un peuple (Ottawa, Les écrits des forges, 1989 [1887]), 74. 
torialement d'un seul tenant depuis la Bourgogne jusqu'à ses États du Nord qui englobaient la Flandre et le Hainaut. Son règne fut ponctué de plusieurs guerres, jusqu'à ce qu'il trouvât la mort devant Nancy, en 1477. L'une de ses campagnes se déroula dans le Nord de la France dont le roi était en train de reprendre le contrôle. Le 27 juin 1472, il se présenta devant la ville royale de Beauvais dont il entreprit le siège. Celle-ci était dépourvue de garnison, mais solidement murée. Le 9 juillet, l'armée bourguignonne se lança à l'assaut de la ville. Mais les habitants, femmes comprises, résistèrent vaillamment. L'une d'elles, Jeanne Laisné, s'empara même d'un étendard des Bourguignons. Finalement, Charles le Téméraire leva le siège le lendemain et la ville resta fidèle au roi $^{13}$. Les hauts faits des femmes de Beauvais et de Jeanne Laisné nous sont connus par deux chartes de Louis XI. La première, de 1473, accordait aux femmes de Beauvais le privilège de marcher devant les hommes, lors d'une procession annuelle en l'honneur de sainte Agadrème qui avait été pieusement invoquée au moment du siège. Elles reçurent également des privilèges vestimentaires sur lesquels nous reviendrons plus loin. Quant à Jeanne Laisné, dont le roi avait déjà favorisé le mariage, elle fut gratifiée, ainsi que son mari, d'une exemption complète d'impôt, durant toute leur vie, par une charte du 22 février 1474 (n.st.) ${ }^{14}$. Ce ne fut que dans la seconde moitié du XVI ${ }^{\mathrm{e}}$ siècle que l'historiographie dota Jeanne Laisné d'une hachette et d'un surnom ${ }^{15}$.

À la différence de Madeleine de Verchères ou de Jeanne d'Arc, Jeanne Hachette n'a laissé aucun témoignage direct à propos de ses actes. Nous connaissons sa geste et celle des femmes de Beauvais par les quelques faits retenus par les deux chartes de Louis XI. Quant à l'histoire de Jeanne d'Arc, elle nous est livrée disloquée par l'acharne-

13. Sur Louis XI et Charles le Téméraire, on peut consulter P. M. Kendall, Louis XI (Paris, Fayard, 1974) et J.-M. Cauchies, Louis XI et Charles le Hardi (Bruxelles, De Boeck, 1996). L'épisode qui nous intéresse fait l'objet de longues considérations dans M. Renet, Beauvais et le Beauvaisis dans les temps modernes. Époque de Louis XI et de Charles le Téméraire (1461-1483) (Beauvais, 1898). L'épisode du siège est bien résumé dans J. Ganiage, Histoire de Beauvais et du Beauvaisis (Toulouse, Privat, 1987), 76-79.

14. Nouveau style: concordance du calendrier de Pâques avec notre calendrier débutant au $1^{\text {er }}$ janvier. Les deux chartes sont publiées dans les Ordonnances des rois de France de la troisième race (Paris, Imprimerie royale, 1723-1849), XVII : 581-584.

15. Plusieurs historiens contestent l'authenticité du surnom Jeanne Hachette, qui serait attribuable à une affabulation de l'historien du XVI ${ }^{\mathrm{e}}$ siècle André Flavyn; voir (A. Florent, Aux temps hérö̈ques de Jeanne Hachette (Paris, Arthème Fayard, 1945), 10 et ss. Nous conservons, dans cet article, la désignation «Jeanne Hachette», nom le plus communément retenu par l'historiographie et la mémoire collective. 
ment des juges qui, à la poursuite d'indices de sa culpabilité, reviennent inlassablement sur les mêmes faits. De nos trois sources, seules les deux relations de Madeleine de Verchères présentent la séquence chronologique complète du cycle d'événements extraordinaires qui font provisoirement d'une femme une guerrière: le temps de paix, l'attaque, le siège et les actions guerrières d'une femme, puis le retour à la paix. La geste héroïque de Madeleine est traduite de façon éminemment expressive dans un système sémantique éclairant les deux autres figures. En conséquence, notre analyse de la femme guerrière prendra pour guide le double récit de Madeleine de Verchères, considéré comme l'expression d'un archétype fournissant un cadre interprétatif du compte rendu du procès de Jeanne d'Arc et des chartes de Louis XI. Ces derniers textes, en revanche, permettent de préciser et de confirmer les traits fondamentaux du modèle qui se dégage des textes de Madeleine. Ensemble, nos sources rendent compte de la complexité des enjeux sociaux en ouvre dans l'inversion sexuelle des rôles, fût-ce dans le cadre exceptionnel de la situation de siège qui l'autorise et la légitime.

\section{LE CADRE SPATIAL DU COMBAT FÉMININ}

L'action des trois femmes se déploie dans un même contexte politico-social. Le motif qui pousse deux d'entre elles à agir est la défense d'un lieu très circonscrit qui est leur habitat, alors que la troisième, Jeanne d'Arc, combat pour la France. Dans les trois cas, le lieu défendu s'inscrit dans une organisation de l'espace très complexe qui donne sens aux actions des protagonistes. On y distingue des «pays» - au sens du pagus gaulois — dont les contours sont définis par la géographie physique et par le tissu de valeurs sociales que partage la communauté humaine qui les habite. Les habitants de ces pays obéissent également à une autorité publique, en l'occurrence le roi de France. Ce roi règne «par la grâce de Dieu». Le christianisme délimite la frontière ultime de l'espace de leur action. Analysons successivement le cadre spatial des actions des trois combattantes, pour en dégager les traits communs.

Le lieu que défendit Madeleine de Verchères est désigné par ellemême, dans sa première lettre, comme le «fort de Vercheres qui est a mon pere ». Ce fort se situait dans un espace géographique qu'elle nomme plusieurs fois, «Canada», et ses habitants, «canadiens». Elle se désigne elle-même par cet ethnonyme. Dès le début de la première lettre, elle reconnaît le Canada comme «ma patrie». Mais, dans son discours, «Canada» ou «canadien» ne s'oppose pas à «France» ou 
«françois» qui opèrent à un niveau générique plus englobant. La France de Madeleine de Verchères est diversifiée et compte plusieurs pays, dont le Canada ${ }^{16}$.

Dans sa première lettre, Madeleine se réclame d'un précédent pour se justifier, en tant que femme, d'avoir pris les armes. Elle écrit en effet que: «il y a eu en France des personnes de mon sexe dans cette derniere guerre, qui se sont mises a la teste de leurs paisant pour s'opposer a l'invasion des ennemis qui entroient dans leurs province. » Frédéric de Kastner a suggéré qu'elle fait allusion ici à Philis de la Tour-du-Pin-La-Charce qui, également en 1692, avait pris la tête de ses vassaux et paysans pour s'opposer à une invasion du Dauphiné par le duc de Savoie. Madeleine avait pu connaître l'événement par son père, originaire de Saint-Chef, en Dauphiné ${ }^{17}$. Pour elle, la France était donc partagée en provinces.

La diversité de la France est également attestée dans sa seconde relation. Mademoiselle Marguerite Antiôme, arrivée inopinément au milieu du siège, se trouvait fort apeurée. Dans une remarque significative quant à l'identité propre de ceux qui étaient nés en terre canadienne, Madeleine juge, sans doute non sans fierté, que le sentiment de mademoiselle Antiôme est «naturel à toutes les femmes parisiennes de nation». Marquant sa différence par rapport aux femmes nées à Paris, Madeleine singularise celles-ci comme appartenant à une «nation», au sens ancien du terme, qui lui fait désigner une communauté humaine habitant une aire géographique limitée et partageant les mêmes coutumes et la même façon de parler ${ }^{18}$. Suivant la même

16. G. Carpin a bien montré, dans Histoire d'un mot. L'ethnonyme Canadien de 15351691 (Sillery, Septentrion, 1995), que le terme «canadien» était devenu d'un usage courant, depuis les années 1660, pour désigner les gens natifs de la Nouvelle-France. La suite de notre analyse du texte de Madeleine de Verchères suggère cependant que les termes «Canada» et «canadiens» ne s'opposent pas à «France» et «françois » comme l'auteur le laisse entendre à la page 155 .

17. F. Kastner, «Marie Madeleine de Verchères », Héros de la Nouvelle France (Québec, 1902), 88. Sur Philis de la Tour, voir également François Aubert de la Chenaye-Desbois, Dictionnaire de la noblesse (Nancy, Berger Levrault, 1980), 10: col. 98. Sur l'origine du père de Madeleine, voir l'article «Jarret de Verchères, Pierre», Dictionnaire biographique du Canada (Québec, Les Presses de l'Université Laval, 1969), II : 306-307. Saint-Chef est situé dans l'actuel département de l'Isère, à une douzaine de kilomètres de la ville de la Tour-du-Pin.

18. Il faut se rappeler que «nation» est un calque du mot latin natio qui vient du verbe latin nascere, «naître». Il désigne les gens ayant une origine commune proche, presque familiale. Le Dictionnaire du moyen français de A. J. Greimas et T. M. Keane (Paris, Larousse, 1992) atteste au mot «nation» que le chroniqueur du XIV siècle, Jean Froissart, l'utilise de la même façon que Madeleine de Verchères, lorsqu'il parle des gens « de la nation de Londres ». Le terme est à rapprocher de «patrie» qu'elle utilise pour désigner le Canada, et qui vient de pater «père» et qui désigne là où l'on est né. Le terme semble toutefois prendre un sens plus 
logique, elle utilise également le mot «nation» pour désigner les différents groupes autochtones du Canada. Ainsi écrit-elle que la mission du gouverneur Beauharnois est de contenir «toutes les nations sauvages dont nous nous sommes environnés».

Qu'est-ce qu'être «françois» pour Madeleine de Verchères? Le terme revient quelques fois et il sert toujours à départager l'ami de l'ennemi. Parlant de sa détermination à défendre le fort de Verchères, elle écrit: «qu'il estoit d'une consequence infinie qu'ils [les ennemis] n'entrassent dans aucun fort françois.» Encore dans la seconde relation qui fait durer le siège huit jours, lorsque, enfin, arrive le secours d'une troupe commandée par monsieur de La Monnerie, «pour reconnoitre à la voix si c'estoient sauvages ou françois, je leur demanday 'qui estes vous'. Ils me répondirent 'François' ». «François» ami s'oppose à «sauvage» ennemi. La même idée se retrouve à la fin de la relation, lorsqu'elle dit de monsieur de Beauharnois qu'il «n'a point d'autre attention que de mettre notre colonie à couvert de l'irruption des Barbares, et d'y faire fleurir la gloire du nom 'françois'». «François » regroupe tous ceux pour qui le combat trouve sa justification dans la fidélité au roi de France ${ }^{19}$. Dès le début de sa première lettre, Madeleine de Verchères souligne qu'il est arrivé à «plussieur de ma patrie de donner des preuves du zele ardent qu'ils ont pour le service du prince». Elle affirme plus loin, qu'à l'égal des femmes de France qui défendirent leur province, «les Canadiennes n'auroient pas moins de passion de faire eclatter leurs zele pour la gloire du roy ». Dans la seconde relation, elle stimule la pugnacité de ses deux jeunes frères en leur rappelant les «leçons que mon pére vous a si souvent donné, que des gentils hommes ne sont nés que pour verser leur sang pour le service de Dieu et du Roy». En fin de compte, Madeleine de Verchères atteste que la population née sur les bords du Saint-Laurent avait développé un attachement à un nouveau pays, le «Canada», qui, sous ce rapport, s'opposait à celui de Paris ou du Dauphiné, mais qui, avec eux, faisait partie du royaume de France et obéissait à son roi ${ }^{20}$.

large, lorsqu'elle écrit dans la deuxième lettre: «nous combattons pour notre patrie et pour la religion. »

19. Rappelons que l'histoire des termes «France» et «françois» est extrêmement complexe. «France» désigne à l'origine la région appelée aujourd'hui «Île-de-France». Ce sens demeure vivant certainement jusqu'à la fin du Moyen Âge et les voyageurs le lisent encore de nos jours lorsque leur avion atterrit à «Roissy-en-France». C'est à partir du XIII ${ }^{\mathrm{e}}$ siècle que le mot acquit progressivement son second sens pour désigner l'ensemble du territoire sur lequel règne le roi. Voir à ce sujet M. Lugge, «Gallia» und «Francia» im Mittelalter (Bonn, L. Rohrsheid, 1960), 160-169.

20. B. Guenée a bien décrit ce double système d'appartenance pour le $X^{\mathrm{e}}$ siècle dans «Un royaume et des pays: la France de Michel Pintoin», dans R. Babel et J.-M. Mœglin, Identité régionale et conscience nationale en France et en Allemagne du Moyen Âge à l'époque 
Il se dégage des textes que nous venons d'examiner une synonymie entre le fait d'être Français et de combattre pour le roi. C'est que, dans la France d'Ancien Régime, la guerre était devenue un droit régalien incontesté, qui avait été acquis lentement, depuis le XIII ${ }^{e}$ siècle, à la suite de multiples initiatives pour contenir, puis interdire la guerre privée ${ }^{21}$. À l'époque de Madeleine de Verchères, une guerre juste ne pouvait être conduite qu'au nom du roi, et opposer ses sujets à ses ennemis. On ne pouvait plus combattre à titre privé. Le fort était celui de son père, mais c'est au nom du roi qu'elle le défendit, pour qu'il restât français. De même, monsieur de Beauharnois rendait «redoutable le nom de notre invincible monarque à tous les ennemis, et respectable et aimable à tous ses sujets ». Bien qu'originaires de différentes provinces, nations ou patries, les combattants guerroyaient en tant que Français sujets du roi. Leurs actions martiales s'inscrivaient dans l'ordre politique et relevaient de ce fait de l'ordre public. Devenant combattante, la femme opérait donc une double transgression: d'une part, en exerçant une fonction masculine et, d'autre part, en quittant l'aire domestique, réservée aux femmes, pour agir dans la sphère publique, réservée aux hommes ${ }^{22}$.

Sur cet espace sociopolitique se superposait la dimension spirituelle, plusieurs fois évoquée par Madeleine de Verchères dans sa seconde relation. Dès qu'elle se vit poursuivie par les Iroquois, elle invoqua la Vierge Marie pour qu'elle la protégeât. Par la suite, c'est Dieu qui lui donna la force, l'inspira et la conforta: «j'eprouvay que quand Dieu donne des forces il n'y a rien d'impossible.»C'est également pour Dieu qu'elle combattit. Sans l'appui de la puissance divine, il lui aurait paru téméraire de penser triompher, mais «quand Dieu gouverne les choses, l'on ne peut que bien reussir». Dans la mentalité chrétienne, l'intervention favorable de l'au-delà confirmait la justesse d'une cause. Madeleine ne manifesta d'ailleurs aucun doute à ce sujet: elle dépeint l'ennemi iroquois dans son absolue altérité. Elle l'oppose aux Français, en le désignant plusieurs fois comme «sauvage» ou comme «barbare», et elle l'exclut du champ du

\footnotetext{
moderne (Sigmaringen, Thorbecke, 1997), 403-412. Il conclut son analyse en constatant «la coexistence de deux sentiments aussi naturels l'un que l'autre mais de caractères différents: l'amour du royaume et l'amour du pays ». La force de l'appartenance au pays et la diversité de la France qui en découle se sont perpétuées jusqu'au XIX ${ }^{\mathrm{e}}$ siècle comme nous le verrons plus loin.

21. Voir à ce sujet, F. Lot et R. Fawtier, Histoire des institutions au Moyen Âge, II: Institutions royales (Paris, Presses universitaires de France, 1958), 426-430.

22. M. McLaughlin, «The Woman Warrior...», loc. cit., a souligné que l'interdit de combattre fait aux femmes fut renforcé par le fait que la guerre, d'activité privée au temps féodal, était devenue une activité de droit public, à la fin du Moyen Âge.
} 
christianisme en le disant «païen». Si la sujétion au roi de France départageait les amis des ennemis, la bénédiction divine fournissait la confirmation ultime de la justesse de la cause.

C'est dans un espace aussi complexe, mais tout à fait analogue, que se déroulèrent, $a u X V^{\mathrm{e}}$ siècle, les actions de Jeanne d'Arc et de Jeanne Hachette. Examinons l'une et l'autre plus brièvement.

Jeanne d'Arc se distingue au départ par le fait qu'elle livra ses combats loin de sa terre natale. L'espace de sa geste est construit sur une opposition entre son lieu domestique, Domrémy, tout près de Vaucouleurs, où s'opéra sa transformation en guerrière, et l'espace public de la France, qu'elle gagna pour se mettre au service du dauphin et pour combattre. De nombreuses fois, au cours des interrogatoires, elle répéta qu'elle «voulait aller en France ${ }^{23} »$. Ce déplacement s'accompagna d'une légère transformation de son nom: chez elle (in partibus suis), on l'appelait «Jeannette», mais depuis qu'elle était en France, on la dénommait «Jeanne ${ }^{24} »$. Bien que le texte ne permette pas une analyse poussée de la question, on perçoit que la France de Jeanne d'Arc correspondait au territoire qui obéissait directement au roi. Domrémy, située dans le comté de Bar, n'était pas en France. De même La Charité-sur-Loire dont elle fut amenée à faire le siège en 1429: interrogée à ce propos, elle soutint qu'elle aurait préféré ne pas y participer et plutôt retourner «en France ${ }^{25}$ ». Cette ville était située dans le comté de Nevers qui faisait partie des terres du duc de Bourgogne, allié des Anglais.

Inspirée par ses voix, sa première ambition fut la libération d'Orléans qu'assiégeaient les Anglais ${ }^{26}$. Cette ville symbolisait également le siège plus étendu que les ennemis imposaient à la France. Dans sa lettre de défi, adressée au roi d'Angleterre, au moment de livrer la bataille pour Orléans, Jeanne écrit: «je sui chief de guerre, et en quelque lieu que je actaindray voz gens en France, je les en ferai

23. Dixit quod ipsa volebat ire in Franciam, P. Champion, op. cit., 40. Le mot «Francia» de l'index permet de retrouver les nombreuses occurrences de l'expression. Ce passage de Domrémy à la France constitua également pour elle une rupture avec sa famille et avec sa condition féminine, comme l'a finement montré M. Delcourt dans «Le complexe de Diane dans l'hagiographie chrétienne», Revue de l'histoire des religions, 77 (1958): 1-33.

24. In partibus suis vocabatur Johanneta, et postquam venit in Franciam, vocata est Johanna, P. Champion, op. cit., 34.

25. Respondit quod ipsa volebat venire in Franciam; sed homines armorum dixerunt ei quod melius erat ire primo ante villam de Caritate, ibid., 83. La Charité-sur-Loire est située dans l'actuel département de la Nièvre.

26. Vox illa sibi dicebat quod levaret obsidionem, coram civitate Aurelianensi positam, ibid., 39. Elle revint plusieurs fois sur cette idée au cours de son interrogatoire. 
aler, vueillent ou non vueillent ${ }^{27}$. Jeanne poursuivait un seul objectif: «elle avait grande volonté et désir que son roi retrouvât son royaume $^{28}$.» C'est toutefois Dieu qui garantissait la justesse de son combat. Toujours dans la lettre de défi, elle dit: «rendez à la Pucelle, qui est cy envoiée de par Dieu, le Roy du ciel, les clefs de toutes les bonnes villes que vous avez prises et violées en France.» Interrogée par ses juges si Dieu haïssait les Anglais, elle répondit ne pas le savoir, mais être certaine en revanche «que Dieu envoyera victoire aux François, et contre les Anglois ${ }^{29}{ }$. D'ailleurs, Jeanne se disait en contact constant avec l'au-delà par l'intermédiaire de ses voix, tantôt celles de sainte Catherine et de sainte Marguerite, tantôt celles de saint Michel ou de saint Gabriel, qui lui dictaient sa conduite.

Quant au lieu que défendit Jeanne Hachette, c'était sa ville, Beauvais. Sous ce rapport, elle se rapproche de Madeleine de Verchères. Elle aussi combattit pour le roi. La charte rappelle à propos des habitants de Beauvais: "la très-grant, entiere, vraye et parfaite loyaulté que ont eue de toute ancienneté et inviolablement conservée et monstrée par effect envers noz predecesseur Roys de France, nous et nostre couronne, à l'encontre de tous les ennemis et adversaires de nous et de nostredict royaume ${ }^{30}$.» L'adversaire était le duc de Bourgogne qui devait hommage au roi de France pour une bonne partie de ses terres. Sa guerre contre Louis XI était qualifiée de rébellion. La charte royale décrit les assiégeants de Beauvais comme «l'armée illicite et effrenée multitude des Bourguignons, noz rebelles et desobeissans subjects ${ }^{31} »$. Enfin, avant toute résistance, les femmes de Beauvais, avec le clergé de la ville, avaient organisé une procession et promené les reliques de sainte Agadrème ${ }^{32}$. Comme pour Jeanne d'Arc et Madeleine de Verchères, Dieu se rangea aux côtés de Jeanne Hachette et des gens de Beauvais, et il légitima leur victoire.

Cette première analyse tend à montrer que la geste de nos trois héroïnes se déploya dans une organisation semblable de l'espace. L'état de siège d'un lieu très menacé servit d'amorce à leur action. Elles combattirent toutes trois pour le roi qui régnait sur une France

27. Ibid., 198.

28. Habebat magnam voluntatem seu affectionem quod rex suus haberet regnum suum, ibidem, 49.

29. Ibid., 145.

30. Ordonnances des rois de France, op. cit., 581.

31. Ibid.

32. «Invocation par elles devotement faicte au nom de Dieu nostre benoist createur, et des merites et intercessions de madame Saincte Agadresme, en l'aide et deffense de la dicte ville», ibid. 
multiple. L'acceptation ou le rejet de l'autorité royale départagea pour chacune des trois l'ami de l'ennemi. Quittant momentanément leur espace privé domestique, elles investirent par leur action guerrière l'espace public de la souveraineté royale ${ }^{33}$. Enfin, les trois trouvèrent dans la bénédiction céleste la confirmation du bon droit de leur cause. Le $\mathrm{XV}^{\mathrm{e}}$ siècle comme le XVII ${ }^{\mathrm{e}}$ siècle ignoraient tout de l'État-nation qui tend à réunir l'appartenance politique et le sentiment d'enracinement dans un espace d'origine. La France d'Ancien Régime se divisait en de multiples pays, qui se distinguaient par leurs coutumes juridiques locales, le parler des gens, leur façon d'occuper le sol et d'y construire leur habitat ${ }^{34}$. Cette diversité survécut jusqu'au début du $\mathrm{XX}^{\mathrm{e}}$ siècle. F. Braudel rappelle qu'Eugen Weber, examinant la France de 1900, «s'aperçoit qu'elle s'égrène entre ses doigts en une multitude de Frances particulières, prêtes à s'éloigner les unes des autres et à se méconnaître ${ }^{35} »$.

\section{L'INVERSION DES RÔLES}

\section{DANS LE CONTEXTE DE L'ÉTAT DE SIÈGE}

L'analyse du cadre spatial a montré que le fait de combattre introduisait la femme dans le domaine public. Devenir guerrière relevait en quelque sorte d'une double transgression. La première tenait à cette intrusion dans une sphère réservée aux hommes, la seconde au geste même de prendre les armes. Cette double rupture d'interdit n'était tolérable qu'en vertu de son caractère exceptionnel et temporaire. Elle comportait toutefois ses risques de dérapage, comme le montre le dénouement de l'histoire de Jeanne d'Arc qui ne parvint pas à réintégrer son rôle féminin.

Tels que racontés par Madeleine, les événements du siège de Verchères évoquent une véritable performance rituelle qui n'est pas sans rappeler le phénomène des rites d'inversion, bien connu des anthropologues, sorte de jeu social parodique où, par exemple, les femmes se comportent de manière excessive comme des hommes. L'inversion sexuelle correspond à une rupture d'interdit «dans la

33. L'histoire de la genèse de l'État moderne a fait l'objet de nombreux travaux depuis une vingtaine d'années. Pour un état de la question, voir les ouvrages cités à la note 6 .

34. Faut-il rappeler que l'unité juridique de la France ne se fera qu'avec la promulgation du Code civil, en 1804 (F. Furet, La Révolution. 1770-1880 (Paris, Hachette, 1988), 238-240), que l'unification des mesures par l'adoption du système métrique date de 1791 et que l'imposition d'un français uniforme, aux dépens des dialectes et des langues régionales, souhaitée à la Révolution, ne se réalisera effectivement qu'au $\mathrm{XX}^{\mathrm{e}}$ siècle; voir à ce sujet les chapitres pertinents dans J. Chaurand, dir., Nouvelle histoire de la langue française (Paris, Seuil, 1999).

35. F. Braudel, L'identité de la France. Espace et Histoire (Paris, Arthaud-Flammarion, 1986), 29. 
mesure où elle met en cause les rôles et les différences instituées par la société, rôles et différences qu'il est impossible et dangereux d'ignorer en temps ordinaire ${ }^{36} »$. Selon l'anthropologue Marc Augé, l'inversion ne vise nullement à nier ou à abolir les différences entre les sexes. Elle semble plutôt les mettre en scène jusqu'au paroxysme, les dramatisant ou les tournant en dérision par l'accumulation extravagante de comportements intempestifs et provocants. L'autre sexe peut s'y trouver ridiculisé, que ce soit par des paroles moqueuses ou grossières, ou par le travestissement qui réduit l'un ou l'autre de ses attributs à un objet fétiche, comme le chapeau de soldat que s'approprie Madeleine, par exemple, et qui suffit à faire d'elle une combattante, la plus brave d'entre les braves!

La référence aux rites d'inversion paraît d'autant plus appropriée que l'on retrouve dans le récit de Madeleine les trois temps correspondant aux trois phases rituelles classiquement distinguées par les anthropologues, depuis la théorie d'Arnold Van Gennep développée à propos des rites de passage ${ }^{37}$. Ce dernier a montré qu'il existe une logique universellement mise en œuvre dans les rites qui accompagnent les étapes de la vie ou les changements de statuts, de rôles ou de positions dans la société. Il signale en particulier la récurrence d'une séquence type comportant trois phases: la séparation d'avec l'état antérieur, la marge et, finalement, l'agrégation au nouvel état. On verra que, d'entrée de jeu, avant l'accomplissement de sa transgression, Madeleine de Verchères réalise rituellement sa séparation d'avec le monde des femmes. Quant à la deuxième phase, la marge qui délimite l'entre-deux où se manifestent les comportements d'inversion des rôles, le corps du texte racontant ses exploits militaires y est consacré. Toutefois, contrairement aux situations de rite de passage, la dernière phase de sa geste ne débouche pas sur l'agrégation à un nouvel état ni sur l'acquisition d'un nouveau rôle. La caractéristique propre des rituels d'inversion est, au contraire, d'agir comme une sorte de catharsis pour un retour à l'ordre antérieur des

36. M. Augé, «Quand les signes s'inversent», Communications, 28 (1978) : 55. M. Augé cite l'exemple des jeux d'inversion des prêtresses du vudu (génie) d'Avlekete qui, dans la vie courante et notamment en cas d'épidémies, s'affirment de manière excessive comme «mâles » et comme «divines», se comportant comme aucun homme ne pourrait le faire. Voir aussi G. Labounoux, «La parodie, instrument de pouvoir symbolique», Cahiers internationaux de sociologie, 73 (1982): 233-249.

37. A. Van Gennep, Les rites de passage (Paris, Maison des Sciences de l'Homme, 1969 [1909)]. P. Bonte \& M. Izard, Dictionnaire de l'ethnologie et de l'anthropologie (Paris, Presses universitaires de France, 1991): voir les articles de P. Smith, «Rite», de J.-C. Muller, «Rite de passage» et de G. Lenclud, «Symbolisme». 
choses $^{38}$. Il s'agit, en ce qui nous concerne, du rétablissement de l'ancienne division sexuelle des rôles et de la confirmation de son caractère inéluctable.

\section{MADELEINE DE VERCHÈRES ET JEANNE D'ARC AVANT L'ÉTAT DE SIÈGE}

Les deux récits de Madeleine s'ouvrent sur une représentation parfaitement féminine de l'héroïne. Au moment de l'attaque, elle est à quatre cents pas du fort de son père. Lorsque le domestique lui crie : «Sauvez vous, Mademoiselle, sauvez vous », elle avoue avoir eu très peur et avoir conservé «dans ce fatail moment, le peut d'asseurance dont une fille est capable et peut estre armée». Elle s'en remit au premier recours qui s'offre aux femmes en cas de danger, prier: "en me recommandant à la Sainte Vierge en luy disant du fonds de mon cœur: Vierge sainte, mere de mon Dieu, vous scavez que je vous ay toujours honorée et aimée comme ma chere mere, ne m'abbandonnez pas dans le danger ou je me trouve». De même, les femmes de Beauvais en appelèrent d'abord à Dieu. Devant la gravité du danger qui menaçait la ville, «à leur intercession, le très-glorieux corps reliquaire [de sainte Agadrème] y reposant fut lors porté en procession solempnelle par le clergié d'icelle ville ${ }^{39} »$.

C'est également le comportement d'une jeune fille de la campagne qui fut celui de Jeanne d'Arc avant sa mission. Enfant, elle menait les animaux aux champs, mais, devenue grande, elle cessa de le faire. Elle intégra alors l'espace domestique, apprit à coudre et à filer, et vaqua aux affaires de la maison familiale ${ }^{40}$. Elle se rendait également, avec les jeunes filles de son village, auprès de l'arbre des Dames qu'elles ornaient de chapeaux de fleurs et près duquel elles dansaient ${ }^{41}$. Peut-être fut-elle même promise en mariage. Les juges l'interrogèrent en effet sur le fait qu'elle fut citée devant l'official de

38. C. M. Coates le premier a esquissé une analyse des récits de Madeleine de Verchères où il souligne l'importance du travestissement et du retour final à l'ordre antérieur des choses lorsque la femme assume la fonction masculine de guerrière dans la société d'Ancien Régime. Voir C. M. Coates, «Commemorating the Woman Warrior of New France: Madeleine de Verchères, 1696-1930», Gender and History in Canada (Toronto, Irwin Press, 1996), 120-136.

39. Ordonnances des rois de France, op. cit., 581. On notera que ce sont souvent des intercesseurs féminins qui interviennent entre Dieu et les trois héroïnes: sainte Catherine et sainte Marguerite pour Jeanne d'Arc, sainte Agadrème pour les femmes de Beauvais, et la Sainte Vierge pour Madeleine de Verchères.

40. P. Champion, op. cit., 38 et 48.

41. Sur ces activités, voir P. Champion, op. cit., 49-50. Les juges l'interrogèrent plusieurs fois sur cet arbre, aussi appelé «arbre aux fées », qu'ils soupçonnaient faire l'objet de pratiques magiques et superstitieuses. 
Toul pour rupture d'engagement. Elle répliqua qu'il n'y eut jamais de telle promesse de sa part. Jeune fille, elle eut également conscience de la guerre et elle eut peur: une fois, par crainte des Bourguignons, elle quitta la maison familiale pour se réfugier à Neufchâteau, en Lorraine $^{42}$. Ces quelques traits la font ressembler à n'importe quelle jeune fille de Domrémy.

Dans l'histoire de Madeleine de Verchères, comme dans celle de Jeanne d'Arc, on identifie particulièrement bien les indices de la rupture avec le comportement féminin. Au terme d'une séquence de paroles et d'actions assimilables à une sorte de rite d'investiture, la femme accède au statut de guerrière: les règles du jeu social sont suspendues temporairement et tous les comportements d'inversion deviennent autorisés. La femme passe du monde féminin à celui des hommes et des combattants: elle peut dès lors accomplir des actes héroïques. La fragile légitimité de l'inversion des rôles exige de la guerrière la maîtrise de symboles audibles et visuels clairs, dont le principal est la modification du costume. Toutefois, la séparation ou l'investiture ne réalise pas un changement de nature, mais d'apparence. Il s'agit plutôt d'un subterfuge destiné à rendre les comportements d'inversion acceptables et efficaces. Dans la rhétorique et les précautions oratoires de Madeleine de Verchères, de même que dans la ritualisation de certains de ses gestes et paroles, se lit en filigrane le caractère éminemment subversif pour l'ordre social que représente l'inversion des rôles masculin et féminin ${ }^{43}$.

\section{MADELEINE DE VERCHÈRES ET JEANNE HACHETTE LA SÉPARATION ET L'INVERSION}

Dans sa lettre à madame de Maurepas, Madeleine manifeste un sens aigu de sa coupure avec le monde des femmes. Dans un geste hautement symbolique, se sentant rattrapée par l'Iroquois qui la poursuivait, elle laissa entre ses mains son «mouchoir de col» et, avec lui, sa féminité. Puis, franchissant le seuil du fort et lançant le cri de commandement «Aux armes!», elle clama bien haut sa transformation, tandis que la porte du fort se refermant sur elle consacra la rupture.

42. P. Champion, op. cit., 38. Plus tard, elle précise qu'il n'y avait qu'un seul partisan bourguignon à Domrémy, mais qu'un village voisin, Maxey, était bourguignon (ibid., 48). Il arrivait que les enfants des deux villages se battent au nom de cette opposition. Maxey-surMeuse se trouvait à un kilomètre et demi de Domrémy. Elle fut donc consciente des enjeux de la guerre de Cent Ans dès son plus jeune âge.

43. Pour l'interdit relatif à l'utilisation des armes par les femmes, voir P. Tabet, «Les mains, les outils, les armes ", Les catégories de sexe en anthropologie sociale, L'homme, 19, 3-4 (1979) : 5-61. 
Aussitôt à l'intérieur, sans s'arrêter «aux gemissement de plusieurs femmes désolées de voir enlever leurs maris», elle monta «sur le bastion ou estoit le sentinelle». Et là, poursuivit-elle: «je me métamorphosay pour lors en mettant le chapeau du soldat sur ma teste.» La voilà combattante autorisée aux yeux de tous et de plein droit.

La deuxième relation ne distingue pas aussi clairement une phase quasi ritualisée de séparation, mais le thème revient de façon récurrente. Après avoir fermé elle-même les portes du fort, Madeleine n'eut de cesse de marquer sa différence à l'égard des femmes. Tout l'oppose aux femmes «gémissantes» ou «extrémement peureuses»: elle dit agir «sans avoir egard à mon sexe, ni à la foiblesse de mon aage».

Après avoir pris acte de la pusillanimité des deux soldats terrés dans la redoute où l'on gardait les munitions, elle se convainquit de la nécessité de prendre en main la défense. Pour asseoir la légitimité de son nouveau rôle, elle entama ensuite sa transformation vestimentaire: «sur le champ, je jettay ma coëffe, j'arboray un chapeau.» Ce chapeau est évoqué à deux reprises, notamment lorsqu'elle risque une sortie pour aller à la rencontre de Pierre Fontaine, de sa femme, Marguerite Antiôme, et de sa famille. Elle précise alors qu'elle le portait pour en imposer aux Iroquois. Il est le symbole de son nouveau statut, comme le sera, dans une moindre mesure, le fusil. La prise d'arme accompagne en effet le geste de mettre le chapeau et plusieurs fois elle souligne qu'elle avait en main un fusil. Elle n'évoque aucune autre transformation vestimentaire. Ses deux récits laissent penser qu'elle conserva l'essentiel de son costume féminin. À cette femme, il ne fallait qu'un chapeau et un fusil pour lui insuffler bravoure et pugnacité.

Pendant les huit jours que dura la défense du fort de Verchères, selon la version longue, Madeleine se mit à l'avant plan, dans un rôle taillé à la mesure d'un chef de guerre au-dessus du commun. Elle se posa comme le capitaine fidèle à son poste: «je n'abandonnerois jamais le fort, [...] j'aimois mieux périr que de le livrer aux ennemis. » Le commandement lui allait bien, elle réussit toujours à galvaniser ses pauvres troupes: «je m'apperçus que mon discours avoit fait impression sur les esprits.» Elle eut toutes les audaces, jusqu'à la témérité la plus folle, et protégea tout son monde au mépris de sa propre vie, tirant du canon et s'exposant sur le bastion, fusil à la main.

L'inversion s'accomplit jusqu'à la réciprocité: les positions s'échangent véritablement jusqu'à tourner les uns et les autres en dérision $^{44}$. Madeleine réalisa pas moins de quatre sorties du fort, se

44. M. Augé, loc. cit., 61-62, signale la diversité des rites d'inversion, où l'inversion n'est pas toujours totale, comme son exemple des femmes d'Avlekete le montre. 
montrant plus déterminée et plus habile encore que les Iroquois, «gens d'ailleurs si rusés et si belliqueux », qui y furent «trompés comme ils l'avouérent, dans la suite». Ainsi, ces guerriers reconnus, craints et magnifiés comme un ennemi extrêmement rusé, furent-ils bernés en maintes occasions par des ruses qui ne tromperaient pas un enfant. Lorsqu'elle sortit seule du fort, pour sauver Fontaine, «une contenance si fiére fit croire aux Iroquois qu'il y avoit plus à craindre pour eux que pour nous». Madeleine, affublée de son chapeau, sur un mode parodique, «faisant plussieurs petits mouvements pour donner à connoistre qu'il y avoit beaucoup de monde», se montre plus rusée que ses ennemis et plus brave que ses soldats. En effet, elle ne perd pas une occasion de mettre en contraste sa bravoure avec l'inertie et la couardise des soldats «qui, saisis de frayeur, s'estoient retirés dans la redoute pour se cacher». Elle confine à un rôle passif, presque féminin, les hommes du fort: Laviolette, le domestique, et les deux soldats. À aucun moment, on ne les verra combattre, tandis que les plus faibles ont lutté à ses côtés: le vieillard à qui elle garda sa confiance et ses deux petits frères qu'elle n'eut de cesse d'inciter à la bravoure. Les Iroquois reconnurent qu'ils avaient «perdu du monde par le feu que mes deux jeunes freres et moy avions fait sur eux». Ce seront encore les mêmes qui feront des sorties hors du fort et qui s'exposeront sur les bastions, tandis que les hommes seront relégués du côté des femmes. La dernière nuit de siège, elle somma les hommes valides d'aller à la redoute, l'endroit le plus sûr, avec les femmes, tandis que le vieux domestique et ses frères firent avec elle le quart sur les bastions.

Tous les rôles forts se dissolvent dans la dérision: les Iroquois sont bernés comme des enfants, les soldats traités comme des chiffes molles. Si la crédibilité et l'efficacité de son statut usurpé tiennent aux signes extérieurs de son investiture, cette surcharge de dérision est nécessaire en ce qu'elle tient à distance le danger social que représente une telle inversion.

Les chartes de Louis XI se montrent très peu prolixes sur le thème de l'inversion. Celle concernant les femmes de Beauvais prend tout de même note du caractère surprenant de leur participation active à la défense de la ville. On y lit en effet que celles-ci «se rendirent comme tous aux crenaulx et à la deffense de la muraille de la dicte ville, et illec en très grant audace, constance et vertu de force, largement, oultre existimacion du sexe feminin, mirent la main à la besoingne, à l'imitation des hommes noz bons et loyaulx subgects ${ }^{45}{ }$. C'est à cette

45. Ordonnances des rois de France, op. cit., 582. 
occasion que Jeanne Hachette s'illustra singulièrement. La seconde charte royale explique: «elle gagna et retira devers elle ung estendart ou banniere desdicts Bourguignons ${ }^{46}$.»

Les Bourguignons, pour leur part, ne pouvaient qu'être honteux d'une défaite en partie imputable aux femmes. Aussi, la charte royale ne manque pas de souligner que «lesdicts Bourguignons finalement furent reboutez et se despartirent tous honteusement de au-devant de la dicte ville ${ }^{47}$.» Le sentiment des contemporains est sans doute assez justement traduit par l'historien François de Mayzerat qui raconta les faits soixante-dix ans plus tard. Il rappelle longuement que celui qui est vaincu par les femmes est toujours susceptible de moquerie. Il n'y a jamais loin de l'inversion des rôles à la dérision. Ainsi rapporte-t-il dans ce texte éclairant qu'il faut citer en entier:

Au reste depuis que les armes du Duc eurent ainsi esté rembarrées par des quenouilles, elles ne prosperét plus nulle part. De quoy son fou scut bien se moquer de luy par un plaisant trait. Car comme il faisoit traisner en son armée deux cens pieces de canon, qu'il appelloit les clefs des villes de France, ce maistre bouffon se mit un jour à tournoyer tout autour \& à regarder dessus et dessous, comme un homme fort empêché; tellement que l'ayant obligé à luy demander qu'est-ce qu'il faisoit, il répondit qu'il cherchoit les clefs de la ville de Beauvais, mais qu'il falloit bien que S. A. [sainte Agrademe] ne les eust pas apportées ${ }^{48}$.

La première phrase de la citation évoque de façon saisissante les tabous attachés aux armes, notamment dans certaines sociétés de chasseurs-cueilleurs, où il est interdit aux femmes de toucher aux arcs et aux flèches, sous peine de voir compromettre leur efficacitét ${ }^{49}$. Ainsi, les armées du duc de Bourgogne, après avoir été «rembarrées par des quenouilles », ne connurent plus aucun succès.

\section{JEANNE D'ARC: L'INVERSION INCONTRÔLABLE}

À première vue, on pourrait croire que l'aventure de Jeanne d'Arc suit un schéma identique à celui des deux héroïnes précédentes. Pourtant, chaque trait de sa transformation qui la rapproche du modèle

46. Ibid., 583.

47. Ibid., 582 .

48. F. de Mayzerat, Histoire de France (Paris, 1646), II : 144.

49. Voir P. Tabet, loc. cit.; L. Marshall, The!Kung of Nyae Nyae (Cambridge, Harvard University Press, 1976) et A. Testart, Essai sur les fondements de la division sexuelle du travail chez les chasseurs-cueilleurs (Paris, Éditions de l'École des hautes études en sciences sociales, 1986). 
porte en lui, par son caractère exacerbé, l'annonce du dénouement dramatique de son histoire. Dès le départ, l'accession de Jeanne d'Arc au statut de guerrière est marquée par son travestissement complet. Aussitôt que Robert de Baudricourt accepta de favoriser son entreprise, elle revêtit des habits masculins et ceignit l'épée que celui-ci lui donna. Elle se fit également couper les cheveux à la manière des hommes. Elle ne se contenta pas d'usurper quelques attributs emblématiques, mais abandonna tous les signes apparents de sa féminité, comme les juges ne manquèrent pas de le retenir dans leurs articles accusatoires $^{50}$.

Les premières paroles qui accompagnèrent son inversion semblent avoir relevé plutôt de l'ordre spirituel que militaire. On sait en effet que lors de sa première entrevue avec le dauphin, Jeanne d'Arc lui livra en secret des révélations qu'elle tenait de ses voix. Plusieurs fois Jeanne refusa de livrer la teneur de ce message qui amena le futur Charles VII à croire en sa mission et à la laisser combattre les Anglais.

Une fois en campagne, Jeanne d'Arc avait l'apparence et le comportement de n'importe quel capitaine. Elle portait les vêtements et les armes du guerrier ${ }^{51}$. L'un de ses premiers gestes, au moment de s'attaquer aux Anglais qui assiégeaient Orléans, fut de leur adresser une lettre de défi, comme il était d'usage au Moyen Âge ${ }^{52}$. Interpellant le roi d'Angleterre, son lieutenant en France, le duc de Bedford, et plusieurs autres chefs de guerre, elle les menaça en ces termes: "alez vous ent en vostre païs, de par Dieu; et se ainsi ne le faictes, attendez des nouvelles de la Pucelle qui vous ira voir briefment, à vos bien grans dommaiges.» Elle avertit les Anglais qui ne voudraient pas quitter la France qu'elle les ferait «tous occire». D'un bout à l'autre, elle conserva un ton martial, comme il convenait dans ce type de lettre. Jeanne participa également aux combats. Par deux fois, elle fut blessée, d'abord le 7 mai 1429 devant Orléans, puis le 8 septembre sous les murs de Paris ${ }^{53}$. Jeanne se crut un véritable soldat. Nulle part son témoignage n'exprime un quelconque sentiment d'ambiguïté face à son état de guerrière. Sa foi dans le caractère divin de sa mission lui fit perdre conscience de sa transgression des règles sociales.

50. Rejecto et relicto omni habitu muliebri (ayant rejeté et abandonné tout vêtement féminin), P. Champion, op. cit., 181.

51. Voir la description de ses armes et vêtements et les notes explicatives de P. Champion dans Procès de condamnation de Jeanne d'Arc, II : op. cit. Sur la question du port de vêtements masculins et de son identité sexuelle, voir S. Crane, «Clothing and Gender Definition: Joan of Arc », loc. cit.

52. J. Glénisson, «Notes d'histoire militaire. Quelques lettres de défi du XIVe siècle», Bibliothèque de l'École des Chartes, 57 (1947-1948): 235-254.

53. P. Champion, op. cit., 59 et 42. 
À la différence des deux autres hérö̈nes, Jeanne d'Arc exerça son rôle de guerrière pendant une très longue période. Elle vécut dans un monde totalement masculin les vingt-sept mois que dura son aventure, entre son départ de Vaucouleurs, le 22 février 1429, et sa mort sur le bûcher à Rouen, le 30 mai 1431. Dès qu'elle quitta sa terre natale, elle voyagea onze jours accompagnée d'une escorte de cinq hommes pour se rendre à Chinon. Puis, de campagne en campagne, elle mena toutes ses aventures militaires comme un homme, parmi des milliers d'autres hommes. Ce sont enfin des soldats anglais qui assurèrent sa surveillance dans les prisons de Rouen, jusqu'au dernier jour de sa vie.

\section{MADELEINE DE VERCHÈRES ET JEANNE HACHETTE LE RETOUR À L'ORDRE ANTÉRIEUR}

Transgression permise momentanément, l'exercice de la fonction guerrière par une femme se termine normalement par la paix, qui rétablit l'ordre antérieur et qui exige une marque significative et publique du retour de l'héroïne à son état originel. Ce processus se réalisa pour Madeleine de Verchères avec l'arrivée de la troupe dirigée par monsieur de La Monnerie, qui vint mettre un terme à l'agression iroquoise. Immédiatement, Madeleine renonça d'elle-même à son statut de guerrière. Allant à la rencontre de son sauveur, elle le salua en disant: «soyez le bien venu, je vous rends les armes.» Plus tard elle ajouta: «faites relever mes sentinelles.» Désormais, elle ne se permettait plus de combattre et ne se reconnaissait plus aucune autorité. Porte-parole attitré de la caste militaire, La Monnerie réinstalla Madeleine dans sa condition féminine. À son «je vous rends les armes », il adressa cette réponse « 'Mademoiselle', me répondit-il d'un air galant, 'elles sont en bonnes mains' ». Il s'était adressé à elle en tant que jeune fille et son discours emprunta le ton qui convenait à un homme de son temps pour exprimer sa considération à une personne de l'autre sexe ${ }^{54}$.

Par la suite, Madeleine reçut en récompense des gratifications du roi, à l'instar de Jeanne Hachette et de Philis de la Tour-du-Pin-LaCharce ${ }^{55}$. Enfin, comme elle nous l'apprend elle-même dans sa seconde relation, Madeleine s'était mariée, confirmant sa féminité.

54. L'importance de ce passage a été bien mise en évidence par C. M. Coates, loc. cit.

55. Louis XIV avait gratifié Philis de la Tour-du-Pin-La-Charce d'une pension de 2000 livres. Voir F. Kastner, «Marie Madeleine de Verchères », loc. cit. L'octroi d'une pension à Madeleine de Verchères est attesté par la Lettre du roi à MM Callières et Bochart Champigny, Archives nationales du Canada, Archives des Colonies, série C 11 A, Vol. 19, bobine. 6069, 31 mai 1701: «Sa Majesté [...] est bien aise de leur expliquer au sujet de la Delle de la Verchère à laquelle elle a accordé cette pension vacante, que son intention est qu'elle assiste sa Mère 
Les deux chartes de Louis XI avaient essentiellement une fonction emblématique pour un retour à l'ordre antérieur des choses. Elles gratifièrent les défenseuses de Beauvais de privilèges qui magnifiaient leur condition féminine. Prenons d'abord la charte de février 1473 concernant Jeanne Hachette. On apprend que déjà le roi avait favorisé le mariage «de Colin Pilon et elle, lequel par nostre moyen a esté naguiere traicté $e^{56} »$. Il faut vraisemblablement comprendre que Louis XI avait payé la dot de Jeanne Hachette, pour lui permettre un meilleur mariage. Puis, par la charte même, il les exemptait, elle et son mari, pour toute leur vie, de deux fardeaux très lourds pour les roturiers, soit les tailles, c'est-à-dire l'impôt, et l'obligation de participer au guet sur les murs de leur ville en cas de guerre. Ainsi, les gratifiaitil de deux privilèges habituellement réservés aux nobles. Bien mariée et exempte de charges touchant les gens de sa condition, Jeanne Hachette devenait une femme notable dans la ville de Beauvais ${ }^{57}$.

Les femmes de Beauvais dans leur ensemble furent confirmées dans leur état par l'autre charte de Louis XI. Le roi demanda d'abord que chaque année fût organisée à ses frais une procession commémorative, le jour de la fête de sainte Agadrème. Les femmes allaient y être particulièrement honorées, car le roi ordonna également que: «icelles femmes aillent d'ores en avant en la procession, ainsi par nous ordonnée, incontinent après le clergié, et precedent les hommes icelluy jour.»

Elles furent également gratifiées par la même ordonnance de privilèges vestimentaires. On sait que dans la société de la fin du Moyen Âge, l'habit témoignait de l'état social et qu'il était interdit de porter des vêtements qui n'étaient pas ceux de sa condition. Dans le monde laïque, ces règles somptuaires visaient particulièrement à départager les nobles des non-nobles ${ }^{58}$. C'est donc en allant à l'encontre de ces règles et pour le plus grand honneur des femmes de Beauvais que Louis XI permit:

pendant qu'elle vivra, voulant bien qu'elle luy demeure après la mort de sa mère, et Elle désire qu'ils y tiennent la main.» Cet extrait est tiré du Bulletin des recherches historiques, 38 (1932): 511-512. Notons enfin que le précédent de Philis de la Tour avait pu également inspirer à Madeleine de Verchères sa demande d'une pension au roi, objet de sa première lettre.

56. Ordonnances des rois de France, op. cit., 583.

57. Sur l'importance de la bonne renommée dans la société médiévale, voir le numéro spécial «La renommée» de la revue Médiévales. Langue, texte et histoire, 24 (1993).

58. Voir O. Blanc, Parades et parures. L'invention du corps de mode à la fin du Moyen Âge (Paris, Gallimard, 1997), en particulier le chapitre «Multiplicité vestimentaire, diversité sociale». 
que toutes les femmes et filles qui sont à present et seront cyaprès en ladicte ville, se puissent et chacune d'icelles à tousiours, le jour et sollempnité de leurs nopces, et toutes autres foiz que bon leur semblera, parer, vestir et aourner de tels vestemens, atours, paremens, joyaulx et aornemens que bon leur semblera, et dont elles pourront recouvrer, sans ce que, pour raison de ce, elles ne aucune d'elles en puissent estre aucunement notées, reprinses ou blasmées, pour raison de quelque estat ou condicion qu'elles soient ne autrement.

Les femmes de Beauvais pouvaient désormais porter sans inquiétude des parures réservées aux nobles. On leur permettait de s'afficher en public avec des insignes propres aux femmes socialement supérieures, en particulier lors de leur mariage, ce jour qui constituait une étape marquante dans l'accomplissement du rôle social féminin. Chargeant les femmes de Beauvais d'un surcroît de féminité, ce privilège somptuaire effaçait en quelque sorte la masculinité des gestes martiaux qu'elles avaient posés à l'encontre des hommes du duc de Bourgogne. L'ordonnance favorisait le retour des femmes à leur état originel. Elle indiquait la voie de sortie d'un rôle pour l'accomplissement duquel il arrivait que des femmes empruntent des éléments du costume masculin.

\section{JEANNE D'ARC}

\section{L'IMPOSSIBLE RETOUR À L'ORDRE ANTÉRIEUR}

La lettre par laquelle le roi d'Angleterre, Henri VI, demanda à l'évêque Pierre Cauchon de juger Jeanne d'Arc, dénonce au premier chef ce crime: «laissant l'abbit et vesteure de sexe feminin, s'est, contre la loy divine, comme chose abhominable à Dieu, réprouvée et défendue de toute loy, vestue, habilée et armée en estat et habit d'omme ${ }^{59}$.» Aux yeux des théologiens, une telle conduite enfreignait le précepte du Deutéronome: «une femme ne portera pas un costume masculin, et un homme ne mettra pas un vetement de femme; quiconque agit ainsi est en abomination à Yahvé ton Dieu ${ }^{60}$.»

Cette question fut l'un des enjeux principaux de son procès et les juges l'examinèrent plusieurs fois en détail ${ }^{61}$. De façon récurrente, ils la pressèrent de questions pour déterminer qui l'avait incitée à se travestir. Assez souvent, elle éluda la question. Une fois, note le compte rendu du procès: «Elle répondit que du vêtement, il importe

59. P. Champion, op. cit., 14.

60. Deutéronome, 22, 5.

61. Voir à ce sujet l'article de M. Delcourt, loc. cit., en particulier 18-28. 
peu, et que c'est la moindre des choses; elle ne prit point les vêtements masculins par le conseil d'un homme du monde; elle ne prit ces vêtements, ni ne fit quoique ce soit, si ce n'est par le précepte de Dieu et des anges ${ }^{62}$.» Les juges retinrent finalement dans leurs chefs d'inculpation que c'étaient les voix de sainte Catherine et de sainte Marguerite qui lui avaient inspiré le port des vêtements masculins ${ }^{63}$.

Mais l'enjeu était-il que Jeanne d'Arc eût porté des vêtements masculins, ou plutôt qu'elle refusa de reprendre son costume de femme? On sait qu'à l'époque de ses premiers contacts avec le dauphin, celui-ci avait demandé aux théologiens de l'Université de Poitiers d'examiner Jeanne sur sa foi et sur sa mission. Marie Delcourt a rappelé que le grand théologien Jean Gerson, favorable à Jeanne d'Arc, leur avait inspiré une interprétation plus nuancée du verset du Deutéronome ${ }^{64}$. On ne lui avait pas tenu rigueur à ce moment de son costume masculin, mieux approprié pour combattre. Bien sûr, elle ne pouvait attendre autant de compréhension de la part de ses juges rouennais, favorables au parti anglo-bourguignon. Néanmoins, lorsqu'on regarde de plus près la position de Pierre Cauchon à cet égard, on voit bien que son principal souci est que Jeanne abandonne dorénavant ses vêtements masculins. Ainsi, lui interdit-il d'entendre la messe et de recevoir les sacrements tant qu'elle n'aura pas repris le costume qui convient à son état.

Finalement, Jeanne se rendit à l'injonction de ses juges au moment de sa sentence. On sait qu'elle fut condamnée à la prison à vie, pourvu qu'elle acceptât d'abjurer ses fautes, ce qu'elle fit effectivement. Elle reconnut avoir fauté très gravement «en faignant mençongeusement avoir eu révélacions et apparicions de par Dieu [...], en portant habit dissolu difforme et deshonneste contre la décence de nature, et cheveux rongnez en ront en guise d'homme, contre toute honnesteté du sexe de femme; en portant aussi armeure par grant présumpcion $^{65}{ }^{\star}$. Elle fut emprisonnée à la suite de sa condamnation le jeudi 24 mai 1431. Dès le lundi suivant, elle fut ramenée devant ses juges comme relapse: en prison elle avait tout de suite remis ses vêtements masculins, retombant dans la faute qu'elle avait abjurée. Pourquoi avait-elle agi de la sorte? Elle répondit entre autres «qu'il luy estoit plus licite de le reprendre et avoir habit d'omme, estant entre

62. Respondit quod de veste parum est, et est de minori; nec cepit vestem virilem per consilium hominis mundi; et non cepit vestem, neque aliquid fecit, nisi per Dei praeceptum et angelorum, P. Champion, op. cit., 55.

63. Ibid., 271.

64. M. Delcourt, loc. cit., 21.

65. P. Champion, op. cit., 367. 
les hommes, que de avoir habit de femme ${ }^{66} »$. Elle était effectivement gardée en prison par des soldats anglais. On connaît la suite : le 30 mai elle périt sur le bûcher comme hérétique.

Le refus de reprendre ses vêtements de femme conduisit Jeanne à son destin fatal. Sa vie se joua sur cette controverse. Jeanne d'Arc n'a pas su trouver la voie de retour à son statut originel qu'imposait la société d'Ancien Régime aux femmes guerrières dont elle acceptait momentanément l'inversion du rôle. Elle n'a pas su comprendre que la société lui indiquait que sa mission était terminée. Jeanne resta sourde aux paroles des hommes, car elle n'écoutait que ses voix. Or, ces dernières n'avaient pas répondu à cette question dramatique entre toutes, qu'elle leur posa un jour durant son procès: «Je sçay bien, quant à l'abit, le commandement comment je l'ay prins; mais je ne sçay point par quelle manière je doy lessier. Pour ce, plaise vous à moy le enseigner ${ }^{67}$.» Jeanne périt pour ne pas avoir su comment redevenir une femme.

\section{CONCLUSION}

Nous avons examiné trois histoires différentes, à partir de trois sources de nature distincte. L'expérience de chacune des trois femmes se distingue par le temps, le lieu, le contexte et, vraisemblablement, par l'ambition et la personnalité de chaque héroïne. Rien non plus ne suggère que l'expérience de l'une ait influencé les autres. La geste de Jeanne d'Arc fut portée par une vision mystique du politique. Jeanne Hachette s'illustra un jour, peut-être par accident. Quant à Madeleine de Verchères, il est vraisemblable que la précarité de l'implantation européenne en Amérique favorisa l'éclosion en elle de sentiments qui la «portent à la gloire comme a bien des hommes», ainsi qu'elle l'écrit dans sa première lettre ${ }^{68}$.

Les trois sources partagent cependant la caractéristique d'avoir été produites dans le contexte historique immédiat des événements et d'être le reflet et l'expression du système de valeurs qui connota les

66. Ibid., 374.

67. Ibid., 230-231.

68. Ce trait belliqueux de son caractère est à nouveau illustré dans la dernière partie de sa seconde lettre, que nous ne commentons pas dans cet article, où elle raconte que, plus tard, une fois mariée, elle se battit à nouveau contre deux Abénaquis pour défendre son mari. Sa pugnacité se manifesta également dans des combats juridiques épiques, comme en fait foi l'article de C. M. Coates, «Authority and Illegitimacy in New France: the Burial of Bishop SaintVallier and Madeleine de Verchères vs. the Priest of Batiscan », Histoire sociale/Social History, 22,43 (mai 1989) : 65-90. L'idée de la singulière situation des femmes au début de la NouvelleFrance nous est suggérée par les auteures du Collectif Clio, L'histoire des femmes au Québec depuis quatre siècles (Montréal, Les Quinze, 1982), chapitres 1 et 2. 
actions qu'elles rapportent. Sur ce plan sont apparues les convergences. Nous avons vu, en premier lieu, comment les actions de chaque guerrière s'inscrivirent dans un même grand cadre sociopolitique. Madeleine et les deux Jeanne combattirent au nom du roi qui incarnait, par sa personne, l'ordre public qui s'imposait sur les pays de la France et sur son prolongement en terre d'Amérique. Le combat marqua pour chacune son intrusion momentanée dans cet ordre public qui demeura durant tout l'Ancien Régime le champ d'action réservé aux hommes.

Chaque source révèle également le caractère subversif de l'inversion sexuelle des rôles. Au départ, les sources mettent en scène le comportement socialement attendu d'une femme devant la violence. Puis, alors que tout bascule dans le chaos de la guerre, elles montrent comment s'opéra pour chaque héroïne la séparation symbolique d'avec le monde féminin, par des gestes, des paroles et des transformations vestimentaires qui ont rendu plausibles leurs actions militaires. Mais l'inversion autorisée momentanément par la situation de crise devait trouver son issue dans le retour à l'ordre normal des choses, qui passait par l'affirmation superlative des caractères distinctifs des femmes. L'inversion de la femme guerrière devait forcément être temporaire. Le caractère excessif de l'inversion, qui peut aller jusqu'à la dérision de tous les rôles sociaux, confirme le caractère inéluctable de la division sexuelle des rôles, «conférant à celle-ci, l'évidence d'une nécessité de nature», selon les termes de Marc Augé69. Jeanne d'Arc connut une fin tragique parce qu'elle s'était méprise sur son rôle. Ne sachant pas reprendre à temps son statut de femme, elle enfreignit gravement les règles sociales et elle reçut un châtiment à la mesure de sa transgression.

Le système de sens, qui vient d'être dégagé de l'expérience de la femme guerrière, est tiré, pour une part significative, des deux relations de Madeleine de Verchères. Ces deux très beaux textes écrits sur les rives du Saint-Laurent, aux premiers temps de notre histoire, s'avèrent les plus éclairants pour dégager le sens de l'expérience emblématique de la jeune Lorraine et des Beauvaisiennes de la fin du Moyen Âge. Resserrant l'espace et comprimant le temps, l'éclairage conjoint de l'anthropologie et de l'histoire des représentations nous a permis de saisir un aspect du système de valeurs qui détermina pendant longtemps la place respective des hommes et des femmes dans la société occidentale. Sous ce rapport, le cas de ces trois femmes guerrières constitue une expérience historique emblématique pour saisir

69. M. Augé, loc. cit., 67. 
l'ampleur de l'interdit longtemps fait aux femmes d'intervenir de plein droit dans la sphère publique. En effet, il fallut attendre le $\mathrm{XX}^{\mathrm{e}}$ siècle pour que les femmes obtiennent, entre autres, le droit de vote et la possibilité de porter l'uniforme militaire ${ }^{70}$.

\section{ANNEXE 1 \\ Lettre de Madeleine de Verchères à Mme de Maurepas ${ }^{71}$}

Madame,

Nos Canadiens ne reçoivent du bien que sous les auspie de Monseigneur le comte de Maurepas qu'ils regardent comme leur protecteur. Les cruelles guerres que nous avons euës jusqu'à present contre les Irocquois ont donné lieu à plussieur de ma patrie de donner des preuves du zele ardent qu'ils ont pour le service du prince. Quoyque mon sexe ne me permette pas d'avoir d'autre inclinations que celles qu'il exige de moy, cependant permettez moy, madame, de vous dire que j'ay des santiman qui me portent à la gloire comme a bien des hommes.

Le hazard a faiet que me trouvant à l'aage de quatorze ans environ, a quatre cents pas du fort de Vercheres qui est a mon pere, à huiet lieuës de Montreal, dans lequel il n'y avoit qu'un soldat en faction, les Irocquois, qui estoient cachez aux environs dans les buissons, firent tout a coup une irruption sur tous nos habitans dont ils enleverent une vingtaine. Je fut poursuivié par un Irocquois jusques aux portes. Mais comme je conservé, dans ce fatail moment, le peut d'asseurance dont une fille est capable et peut estre armée, je luy laissay entre les mains mon mouchoir de col et je fermay la porte sur moy en criant : «aux armes». Et sans m'arrester aux gemissement de plusieurs femmes désolées de voir enlever leurs maris, je monté sur le bastion ou estoit le sentinelle. Vous dira-jé, Madame, que je me métamorphosay pour lors en mettant le chapeau du soldat sur ma teste, et que faisant plussieurs petits mouvements pour donner a connoistre qu'il y avoit beaucoup de monde, quoyqu'il n'y eut que le soldat, je chargeay moy mesme un canon de quatre livres de balle que je tiré sur eux. Ce coup sy précipité eut

70. Dans l'armée britannique, c'est en 1917 qu'on intègre officiellement le premier corps auxiliaire de femmes portant l'uniforme kaki. Voir R. Terry, Women in Khaki. The Story of the British Woman Soldier (Londres, Columbus Books, 1988). On a souvent souligné l'importance des deux guerres mondiales au $\mathrm{XX}^{\mathrm{e}}$ siècle pour l'émancipation des femmes. Les auteures du Collectif Clio notent à propos de la Seconde Guerre: «La guerre avait pu signifier une transformation dans les rôles pour les unes et les autres. L'après-guerre et la mystique féminine marquent, pour toutes, un retour à des valeurs plus traditionnelles »; Le Collectif Clio, op. cit., 397.

71. Archives nationales du Canada, Archives des Colonies, série F 3, vol. 4, folio 341, bobine 7930 . 
heureusement tout le succez que je pouvois attendre pour avertir les forts voisins de se tenir sur leurs gardes, crainte que les Irocquois ne fissent les mesme coups. Je scay, Madame, qu'il y a eu en France des personnes de mon sexe dans cette derniere guerre, qui se sont mises a la teste de leurs paisant pour s'opposer à l'invasion des ennemis qui entroient dans leurs province. Les Canadiennes n'auroient pas moins de passion de faire eclatter leurs zele pour la gloire du roy si elles en trouvoient l'occasion. Il y a cinquante cinq ans que mon pere est actuellement au service. Sa destinée n'est pas heureuse, la nostre l'est encore moins. Nous regardons Monseigneur de Maurepas comme le soutien du Canada. Pour nous, Madame, honorez-nous, nous autres filles, de vos bontez. Qu'il plaise a vostre generosité me faire avoir une petite pension de cinquante escus, comme a plusieurs femme d'offisié du pais qui en ont. Si je ne puis esperer cette grace, que le bien que vous voudriez me faire rejallisse du moins sur un de mes frere qui est cadet dans nos troupes. Faittes luy donner, s'il vous plaist, une enseigne. Il scait le service. Il s'est trouve dans plusieur expedisions contre les Irocquois. Jen ay mesme eu un brullé par eux. Nous serons obligez de continuer nos prieres a Dieu pour vostre prosperité et celle de Monseigneur de Maurepas.

Je suis avec un tres profond respect, Madame, votre tres humble, tres obeisante et tres respetueuze servante, Marie Magdelaine de Verchere.

De Quebec, le $15^{\mathrm{e}}$ d'octobre 1699.

\section{ANNEXE 2 \\ Relation des faits heroiques de Mademoiselle Marie Madelaine de Verchére contre les Iroquois aagée de quatorze ans en l'année 1696 le $22^{e}$ octobre a huit heures du matin ${ }^{72}$.}

J'estois a cinq arpens du fort de Verchére appartenant au Sieur de Verchére mon pére qui estoit pour lors a Kébek par ordre de Mr le Chevalier de Caliéres Gouverneur de Montréal, et ma mére estoit a Montréal. J'entendis tirer plusieurs coups de fulsil sans scavoir sur quoy l'on tiroit. Bientôt j'apperçus que les Iroquois faisoient feu sur nos habitans qui estoient eloignés du fort environ d'une demi-lieüe. Un de nos domestiques me cria: «Sauvez vous, Mademoiselle, sauvez vous! Voyla les Iroquois qui viennent fondre sur nous! » À l'instant je me détournay, en j'apperçus quarante-cinq Iroquois qui accouroient vers moy, n'en estant éloignés que d'une portée de pistolet. Résolüe de mourir plutôt que de tomber entre leurs mains, je songeay à chercher mon salut dans la fuite. Je courus vers le fort en me recommandant à la Sainte Vierge en luy disant du fonds de mon cœur: "Vierge sainte, mere de mon Dieu, vous scavez que je vous ay toujours honorée et aimée comme

72. Archives nationales du Canada, collection Moreau de Saint-Méry, Archives des Colonies, série F 3, vol. 5, folio 434, bobine 7931 . 
ma chere mere, ne m'abbandonnez pas dans le danger ou je me trouve; j'aime mille fois mieux perir que de tomber entre les mains d'une nation qui ne vous connoit pas. Cependant, les Iroquois qui me poursuivoient, se voyant trop eloignez de moy pour me prendre en vie, auparavant que je pusse entrer dans le fort, et se sentant assez proches pour me tirer à coups de fusil, s'arrêtérent pour faire leur décharge sur moy. Je l'essuyay pendant longtems, ou du moins il m'ennuya fort. Les balles de quarante cinq fusils qui me siffloient aux oreilles me faisant paroitre le tems bien long et l'eloignement du fort bien considerable, quoyque j'en fus bien proche. Estant à portée de me faire entendre, je criay: «Aux armes! Aux armes!», esperant que quelqu'un sortiroit pour venir me secourir. Mais en vain. Il n'y avoit dans le fort que deux soldats qui, saisis de frayeur, s'estoient retirés dans la redoute pour se cacher. Enfin arrivée à la porte, je trouvay deux femmes qui pleuroient leurs marys qui venoient d'etre tués, je les fis entrer malgré elles dans le fort dont je fermay moy-même les portes. Alors je pensay à me mettre moy et le petit nombre de personnes qui m'accompagnoient à couvert des insultes des barbares. Je fis la visite du fort, je trouvay plusieurs pieux tombés qui faisoient des bréches par ou il estoit facile aux ennemis d'entrer. Je donnay mes ordres pour les faire relever et, sans avoir egard à mon sexe, ni à la foiblesse de mon aage, je prenois un pieu par un bout en encourageant les personnes qui estoient avec moy à le relever. J'eprouvay que quand Dieu donne des forces il n'y a rien d'impossible.

Les bréches du fort réparées, je m'en allay à la redoute qui servoit de corps de garde ou estoient les munitions de guerre. J'y trouvay les deux soldats, l'un caché et l'autre qui tenoit un méche allumée. Je demanday à celuy-cy: «Que voulez-vous faire de cette méche»? «C'est pour mettre le feu aux poudres», me répondit-il, «et pour nous faire sauter». "Vous estes un malheureux »! luy répondis-je, «Retirez-vous, je vous le commande»! Je luy parlay d'un ton si ferme et si assuré qu'il m'obéit. Sur le champ, je jettay ma coëffe. J'arboray un chapeau et, prenant un fusil, je dis à mes deux jeunes fréres: «Battons-nous jusqu'à la mort. Nous combattons pour notre patrie et pour la religion. Souvenez-vous des leçons que mon pére vous a si souvent donné, que des gentils hommes ne sont nés que pour verser leur sang pour le service de Dieu et du Roy. Mes fréres et les soldats animés par mes paroles firent un feu continuel sur l'ennemy. Je fis tirer le canon non seulement pour effrayer les Iroquois en leur faisant voir que nous estions en estat de nous bien deffendre ayant du canon, mais encore pour avertir nos soldats qui estoient à la chasse de se sauver dans quelque autre fort.

Mais, que n'a-t-on pas à souffrir dans ces extrémités? Malgré le bruit de notre artillerie j'entendois les cris lamentables des femmes et des enfans qui venoient de perdre leurs marys, leurs fréres et leurs péres. Je crus qu'il estoit de la prudence, pendant que l'on faisoit feu sur l'ennemi, de représenter à ces femmes désolées et à ces enfans le danger auquel nous exposent leurs hurlemens, qui ne pouvoient pas manquer d'etre entendus de l'ennemy, malgré le bruit des fusils et du canon. Je leur ordonnay de se taire afin de ne pas donner lieu de croire que nous estions sans ressource et sans espérance. 
Pendant que je leur parlois de la sorte, j'apperçus un canot sur la rivière vis-à-vis du fort: c'estoit le Sr Pierre Fontaine, avec sa famille, qui venoit débarquer dans l'endroit ou je venais d'être manquée par les Iroquois qui y paroissoient encore à droit et à gauche. Cette famille alloit être défaite, si on ne leur eut donné un prompt secours. Je demanday aux deux soldats s'ils vouloient aller au devant de cette famille pour luy favoriser le débarquement qui estoit à cinq arpens du fort. Leur silence me faisant connoitre leur peu de résolution, je commanday à Laviolette, notre domestique, de faire sentinelle à la porte du fort et de la tenir ouverte pendant que j'irois moy-même au bord de la riviére, le fusil à la main et le chapeau sur la tête. J'ordonnay, en partant, que si nous estions tués l'on fermat les portes du fort et que l'on continuât toujours à se bien deffendre. Je partis dans la pensée que Dieu m'avoit inspirée, que les ennemis qui estoient en présence croyoient que c'estoit une feinte que je faisois pour les engager de venir au fort d'ou l'on feroit une vive sortie sur eux. Ils le crurent effectivement, et ainsy j'eus lieu de sauver ce pauvre Pierre Fontaine, sa femme et ses enfans. Estant tous débarqués, je les fis marcher devant moy jusqu'au fort à la vüe de l'ennemy. Une contenance si fiére fit croire aux Iroquois qu'il y avoit plus à craindre pour eux que pour nous. Ils ne sçavoient pas qu'il n'y avoit dans le fort de Verchére que mes deux jeunes fréres aagés de douze ans, notre domestique, deux soldats et un vieillard aagé de 80 ans, avec quelques femmes et quelques enfans.

Fortifiée de la nouvelle récrüe que me donna le canot de Pierre Fontaine, je commanday que l'on continuât à faire feu sur l'ennemy. Cependant, le soleil se couche. Un nord-est impetueux, qui fut bientôt accompagné de neige et de grelse, nous annonce la nuit la plus affreuse qui se puisse imaginer. Les ennemis, toujours en présence, bien loin de se rebuter d'un tems si facheux, me firent juger par leurs mouvemens, qu'ils vouloient escalader le fort à la faveur des tenébres. J'assemble toutes mes troupes, c'est-à-dire six personnes, auxquelles je parlay ainsy: «Dieu nous à sauvés aujourd'hui des mains de nos ennemis, mais il faut prendre garde de ne pas tomber cette nuit dans leurs filets. Pour moy, je veux vous faire voir que je n'ay point de peur: je prends le fort pour mon partage, avec un homme aagé de 80 ans et un soldat qui n'a jamais tiré un coup de fusil. Et vous, Pierre Fontaine, la Bonté et Galhet [noms des deux soldats] vous irez à la redoute avec les femmes et les enfans comme estant l'endroit le plus fort. Si je suis prise, ne vous rendez jamais, quand même je serois brûlée et hachée en piéces à vos yeux. Vous ne devez rien craindre, dans cette redoute, pour peu que vous combattiez.

À l'instant, je place mes deux jeunes fréres sur deux bastions, ce jeune homme de 80 ans sur le troisiéme, et moy je pris le quatriéme. Chacun fit bien son personnage. Malgré le sifflement du nord-est, qui est un vent terrible en Canada dans cette saison, malgré la neige et la gresle, l'on entendoit à tout moment: «Bon quart!» de la redoute au fort, et du fort à la redoute: «Bon quart !». On auroit cru à nous entendre que le fort estoit rempli d'hommes de guerre. Aussy les Iroquois, gens d'ailleurs si rusés et si belliqueux y furentils trompés comme ils l'avouérent, dans la suite, à $\mathrm{M}^{\mathrm{r}}$ de Calliéres, à qui ils 
déclarérent qu'ils avoient tenu conseil pour prendre le fort pendant la nuit, mais que la garde que l'on y faisoit sans relâche les auroit empêché d'executer leur dessein, surtout ayant déja perdu du monde par le feu que mes deux jeunes freres et moy avions fait sur eux, le jour précédent.

Environ une heure après minuit, la sentinelle du bastion de la porte cria: «Mademoiselle, j'entends quelque chose». Je marche vers luy pour découvrir ce que c'estoit. J'apperçus au travers des ténebres et à la faveur de la neige quelques bêtes à cornes, tristes restes de nos ennemis. L'on me dit: "Il faut ouvrir la porte pour les faire entrer». «À Dieu ne plaise», répartis-je, «vous ne connoissez pas encore tous les artifices des sauvages, ils marchent sans doute après ces bestiaux couverts de peaux de bêtes pour entrer dans le fort, si nous sommes assez indiscrets pour en ouvrir la porte». Je craignois tout d'un ennemy aussy fin et aussy rusé que l'Iroquois. Cependan après avoir pris toutes les mesures que demande la prudence dans ces circonstances, je jugeay qu'il n'y avoit point de risque à ouvrir la porte. Je fis venir mes deux fréres avec leurs fusils bandés en cas de surprise et ainsy nous fimes entrer ces bestiaux dans le fort.

Enfin, le jour parut et le soleil, en dissipant les tenebres de la nuit, sembla dissiper notre chagrin et nos inquiétudes. Je parus aux milieu de mes soldats avec un visage guay, en leur disant: "Puisqu'avec le secours du ciel, nous avons bien passé cette nuit, toute affreuse qu'elle a esté, nous en pourrons bien passer d'autres en continuant notre bonne garde, faisant tirer le canon d'heure en heure pour avoir du secours de Montreal, qui n'est eloigné que de huit lieües. Je m'apperçus que mon discours avoit fait impression sur les esprits. Il n'y eut que Madelle Marguerite Antiôme, femme du $\mathrm{S}^{\mathrm{r}}$ Pierre Fontaine, qui, extrémement peureuse, comme il est naturel à toutes les femmes parisiennes de nation, demanda à son mary de la conduire dans un autre fort, lui représentant que si elle avoit été assez heureuse pour echapper, la prémière nuit, à la fureur des sauvages, elle ne devoit pas s'attendre au même bonheur la nuit suivante: que le fort de Verchére ne valloit rien, qu'il n'y avoit point d'hommes pour le garder, et que d'y demeurer c'estoit s'exposer à un danger evident, ou de tomber dans un esclavage perpetuel, ou de mourir à petit feu. Le pauvre mary, voyant que sa femme persistoit dans sa demande, et qu'elle vouloit se retirer au fort de Contre-Cœur, eloigné de trois lieües de celuy de Verchére, lui dit: «Je vas vous armer un canot d'une bonne voile, avec vos deux enfans qui sçavent bien canoter. Pour moy, je n'abbandonneray jamais le fort de Verchére tandis que Mademoiselle Magdelon y sera (c'est ainsy que l'on m'appeloit dans mon enfance). Je luy fis réponse d'un ton ferme et hardy que je n'abandonnerois jamais le fort, que j'aimois mieux périr que de le livrer aux ennemis, qu'il estoit d'une consequence infinie qu'ils n'entrassent dans aucun fort françois, qu'ils jugeroient des autres par celuy-cy, s'ils s'en emparoient, et qu'une pareille connoissance ne pourroit servir qu'à augmenter leur fierté et leur courage.

Je puis dire avec vérité que je fus deux fois vingt quatre heures sans dormir ny manger; je n'entray pas une seule fois dans la maison de mon pére, je me tenois sur le bastion, ou j'allois voir de quelle manière l'on se com- 
portoit dans laredoute; je paraissois toujours avec un air riant et gay; j'encourageois ma petite troupe par l'espérance que je leur donnois d'un prompt secours.

Le huitiéme jour (car nous fûmes huit jours dans de continuelles allarmes, toujours à la vüe de nos ennemis, et exposés à leur fureur et à leur barbarie), le huitiéme jour, dis-je, $\mathrm{M}^{\mathrm{r}}$ de Lamonnerie, lieutenant détaché de $\mathrm{M}^{\mathrm{r}}$ de Calliéres, arriva la nuit avec quarante hommes. Ne sachant point si le fort estoit pris, il faisoit son approche en grand silence. Un de nos sentinelles, entendant quelque bruit, cria: «Qui vive»?. J'estois pour lors assoupie, la tête sur une table, mon fusil de travers dans mes bras. La sentinelle me dit qu'il entendoit parler sur l'eau. Sans perdre de tems, je montay sur le bastion pour reconnoitre à la voix si c'estoient sauvages ou françois, je leur demanday: «Qui estes vous»? Ils me répondirent: «François, c'est La Monnerie, qui vient vous donner du secours». Je fis ouvrir la porte du fort, j'y plaçay une sentinelle et je m'en allay au bord de l'eau pour le recevoir. Aussytôt que je l'apperçus, je le saluay par ces paroles: «Monsieur, vous soyez le bien venu, je vous rends les armes». «Mademoiselle», me réponditil d'un air galant, «elles sont en bonnes mains». «Meilleures que vous ne croyez », luy repliquay-je. Il visita le fort, il le trouva en tres bon estat, une sentinelle sur chaque bastion. Je lui dis: « $\mathrm{M}^{\mathrm{r}}$ faites relever mes sentinelles afin qu'ils puissent prendre un peu de repos. Il y a huit jours que nous n'avons point descendu de dessus nos bastions. »

J'oubliois une circonstance qui pourra faire juger de mon assurance et de ma tranquillité. Le jour de la grande bataille, les Iroquois qui environnoient le fort faisant bruler les maisons de nos habitans, saccageant et tuant leurs bestiaux à notre vue. Je me ressouvins, à une heure de soleil, que j'avois trois poches de linge avec quelques couvertures hors du fort. Je demanday à mes soldats si quelqu'un vouloit venir avec moy, le fusil à la main, chercher mon linge. Leur silence, accompagné d'un air sombre et morne, me faisant juger de leur peu de courage, je m'addressay à mes jeunes fréres, en leur disant: «Prenez vos fusils et venez avec moy»! - «Pour vous», dis-je aux autres, «continuez à tirer sur nos ennemis, pendant que je vas chercher mon linge». Je fis deux voyages à la vüe des ennemis, dans le lieu même ou ils m'avoient manquée quelques heures auparavant. Ma démarche leur parut sans doute suspecte, car ils n'osèrent venir pour me prendre, ni même tirer pour m'ôter la vie. J'éprouvay que quand Dieu gouverne les choses, l'on ne peut que bien reussir.

Depuis que je suis mariée (l'an 1722) je me suis trouvée dans une occasion assez délicate ou il s'agissoit de sauver la vie à $\mathrm{M}^{\mathrm{r}}$ de La Perrade, mon mary, et a moy. Deux abnakis des plus grands hommes de leur nation, estant entrés chez nous chercher une querelle a $\mathrm{M}^{\mathrm{r}}$ de La Perrade, il leur dit en Iroquois : «Sortez d'icy»! Ils sortirent tous deux tres fachés. Leur sortie, qui fut fort brusque, nous fit croire la querelle finie. Nous n'examinames point leurs démarches, persuadés qu'ils avoient pris le party de s'en aller. Dans un moment, nous fumes fort surpris de les entendre tous les deux dans le tambour de la maison, faisant le cry de mort et disant: «Tagarianguen», 
qui est le nom iroquois de mon mary, «tu es mort»! Ils estoient armés, l'un d'un casse-tête et l'autre d'une hache. Celuy-cy enfonce, brise la porte à coups de hache, entre comme un furieux, la rage peinte sur le visage, leve la hache sur la tête de $\mathrm{M}^{\mathrm{r}}$ de La Perrade, qui fut assez adroit et assez heureux pour parer le coup, en se jettant à corps perdu sur le sauvage. Mais il estoit trop foible pour pouvoir resister longtems à un sauvage d'une stature gigantesque et dont les forces répondoient à la haute taille. Un homme de résolution, qui se trouva fort à propos à la porte de la maison, donna du secours à $\mathrm{M}^{\mathrm{r}}$ de La Perrade. Le sauvage, qui estoit armé d'un casse-tête, voyant son compagnon en presse, entre, leve le bras pour décharger son coup sur la tête de mon mary. Resolüe de perir avec luy, et suivant les mouvemens de mon cœur, je sautay, ou plutôt, je volay vers le sauvage. J'empoigne son casse-tête, je le desarme. Il veut monter sur un coffre, je luy casse les reins avec son casse-tête, et je le vois tomber à mes pieds. Je ne fus jamais plus surprise que de me voir à l'instant enveloppée par quatre sauvagesses. L'une me prend à la gorge, l'autre aux cheveux après avoir arraché ma coëffe, les deux autres me saisissent par le corps pour me jetter dans le feu. À ce moment, un peintre me voyant auroit bien pu tirer le portrait d'une Magdelaine décoéffée, mes cheveux epars et mal arrangés, mes habits tout déchirés, n'ayant rien sur moy qui ne fut par morceaux. Je ne ressemblois pas mal à cette sainte, aux larmes près, qui ne coulèrent jamais de mes yeux. Je me regardois comme la victime de ces furieuses outrées de douleur de voir, l'une son mary, les autres leur parent etendu sur la place sans mouvement et presque sans vie. Bientôt j'allois etre jettée dans le feu, lorsque mon fils Tarieu aagé seulement douze ans animé comme un lion à la vüe de son pere qui estoit encore aux prises avec le sauvage et de sa mere prête à etre devorée par les flammes, il s'arme de ce qu'il rencontra, frappa avec tant de force et de courage sur la tête et sur les bras de ces sauvagesses, qu'il les obligea à lâcher prise. Debarrasée d'entre leurs mains je cours au secours de $\mathrm{M}^{\mathrm{r}}$ de La Perrade, passant sur le ventre de celuy que j'avois etendu par terre. Les quatre sauvagesses s'estoient déjà jettée sur $\mathrm{M}^{\mathrm{r}}$ de La Perrade pour luy arracher la hache qu'il tenoit et dont il vouloit casser la tête au malheureux qui venoit de le manquer. Prenant le sauvage par les cheveux, luy dit: «Tu es mort, je veux avoir ta vie». Le François dont j'ay parlé, qui donnoit secours à $\mathrm{M}^{\mathrm{r}}$ de La Perrade, me dit: «Madame, ce sauvage demande la vie, je crois qu'il faut luy donner quartier. Nous ne sçavons si ces femmes ne sont point armées de couteaux ». En même tems, ces sauvagesses, qui jusqu'alors avoient toujours poussé des cris effroyables qui nous empêchoient de nous entendre, demandérent aussy la vie. Nous voyant les maitres, nous crumes qu'il estoit plus glorieux de pardonner à notre ennemi vaincu que de le faire mourir. Ainsy, je sauvay la vie à mon mary, et mon fils aagé douze ans sauva la vie à sa mére. Cette action fut aux oreilles de $\mathrm{M}^{\mathrm{r}}$ de Vaudreuil. Il voulut s'informer du fait par luy-même. Il vint exprés sur les lieux, il vit la porte cassée, il parla au François temoin de l'action, et sçut, dans la suite, des sauvages mêmes, la verité de ce que je viens d'exposer.

Voylà la narration simple et juste de mon aventure, qui m'a déjà procuré des graces de sa Majesté, et que je n'aurois pas pris la liberté de rediger par 
ecrit, si $\mathrm{M}^{\mathrm{r}}$ le Marquis de Beauharnois, notre illustre gouverneur, qui n'a point d'autre attention que de mettre notre colonie à couvert de l'irruption des Barbares, et d'y faire fleurir la gloire du nom «françois», en rendant redoutable le nom de notre invincible monarque à tous les ennemis, et respectable et aimable à tous ses sujets, ne m'avoit engagée à faire ce détail. Sa sagesse ne se contente pas de contenir toutes les nations sauvages dont nous nous sommes environnés dans le respect et dans la crainte, et de tenir eloignés à quatre ou cinq cens lieües les ennemis de l'estat. Son infatigable application aux affaires les plus serieuses n'estant interrompüe que par l'attention qu'il donne à ce qui s'est passé de plus considerable depuis l'établissement de cette colonie, il le fait valoir avec cette bonté et cet air noble et grand, qui luy sont si naturels. Il le propose pour exemple, afin d'animer de plus en plus les sujets du Roy à se distinguer par des actions eclattantes lorsque l'occasion s'en presentera. 